UNIVERSIDADE DE SÃO PAULO

FACULDADE DE ODONTOLOGIA

\title{
ESTUDO DA INTERFACE ADESIVA EM RESTAURAÇÕES \\ QUE COMBINAM RESINAS COM DIFERENTES MÓDULOS DE \\ ELASTICIDADE
}

\section{SILVIA KENSHIMA}

Dissertação apresentada à Faculdade de Odontologia da Universidade de São Paulo, para obter o Título de Mestre, pelo Programa de Pós-Graduação em Odontologia.

Área de Concentração: Materiais Dentários

São Paulo 
UNIVERSIDADE DE SÃO PAULO

FACULDADE DE ODONTOLOGIA

\section{ESTUDO DA INTERFACE ADESIVA EM RESTAURAÇÕES \\ QUE COMBINAM RESINAS COM DIFERENTES MÓDULOS DE \\ ELASTICIDADE}

\section{SILVIA KENSHIMA}

Dissertação apresentada à Faculdade de Odontologia da Universidade de São Paulo, para obter o Título de Mestre, pelo Programa de Pós-Graduação em Odontologia.

Área de Concentração: Materiais Dentários

Orientadora: Prof ${ }^{a} r^{a}$ Rosa Helena Miranda Grande

São Paulo 
Data da Defesa:

Comissão Julgadora

Prof. Dr.

Julgamento:

Assinatura:

Prof. Dr.

Julgamento:

Assinatura:

Prof. Dr.

Julgamento:

Assinatura: 


\section{DEDI CO ESTE TRABALHO...}

Aos meus pais,

Obrigada por me ensinarem desde pequena a perseverar nas coisas que acredito e terem acompanhado cada um de meus passos com muito amor e aquele apoio incondicional de quem sempre acreditou em mim. Eu gostaria de dedicar este trabalho em especial a vocês com todo meu carinho porque este sonho só se tornou realidade porque sonhamos juntos.

Às minhas irmãzinhas,

Obrigada pelo carinho, pela meiguice e pelo apoio em silêncio dos seus olhinhos que brilhavam acreditando em mim. Espero poder corresponder sempre e que continuemos além de irmãs amigas pra toda hora.

Aos meus avós

Sei que vocês estão compartilhando desta alegria e estarão sempre no meu coração. 
À Prof ${ }^{\mathrm{a}}$ Rosa,

Não há como agradecer pela amizade e confiança

que sempre depositou em mim. Seu apoio foi

fundamental para que eu superasse as

dificuldades e pudesse crescer no meu

aprendizado. Seu desprendimento e caráter são

marcantes e eu a admiro muito por estar

constantemente lutando pelo que é certo. Esta

luta exige muita coragem e apenas pessoas

autênticas como você podem fazer isso.

Ao Prof. Rafael,

Gostaria de dedicar este trabalho a você também porque simplesmente a palavra obrigada e seus sinônimos são insuficientes para agradecê-lo. Você me iniciou nessa jornada apaixonante pelos "porquês"... Foi um grande privilégio para mim ter podido contar com a co-orientação de alguém que tem 0 seu desprendimento e o seu espírito de pesquisador nato. Seu entusiasmo e empenho sempre foram contagiantes e um estímulo importantíssimo para superar todas as dificuldades que a pesquisa nos impõe. Você é uma das pessoas que me fazem pensar que a amizade e a paixão pelas descobertas de cada dia fazem parte daquelas coisas que fazem a vida valer a pena. 


\section{AGRADECIMENTOS}

Ninguém consegue fazer nada sozinho. Se este sonho se tornou realidade é porque tive o apoio de todos e esta conquista também é de vocês.

\section{Muito obrigada ao Departamento de Materiais Dentários e àFOUSP.}

Meus agradecimentos especiais aos professores:

Antônio Muench, impossível não te admirar... Você é um grande exemplo para todos nós. Sua vitalidade, disposição e a solicitude com que sempre me ajudou desde o tempo de minha iniciação científica são lições de vida que guardarei com carinho do grande mestre que você é.

Leonardo Rodrigues Filho, obrigada pela amizade e pelo apoio. Você assistiu minha primeira aula e sempre foi um grande incentivador dos meus "ensaios didáticos". Seu espírito crítico também trouxe contribuições importantes para 
este trabalho e me ajudaram com seu delineamento experimental.

Joel Bianchi,(“in memorian”) são muitas as saudades... Gostaria de um dia conseguir dar aula com o mesmo entusiasmo e carisma com que você as ministrava. Com a arte que só quem tem amor pelo ensino como você consegue expressar.

Júlio da Mota Singer, obrigada de coração... Sei que você é muito ocupado, mas assim mesmo sempre arrumou um tempinho para me "socorrer". Sinto-me muito honrada em poder contar com seu suporte estatístico neste trabalho.

Gostaria também de agradecer a todos os demais professores que, embora não tenham sido mencionados individualmente contribuíram de modo importante com minha formação não só pelas informações trocadas como pelo incentivo. 
Meus agradecimentos aos grandes colaboradores:

Antonio Carlos Lascala, a sua ajuda foi essencial no desenvolvimento não apenas deste como de todos os trabalhos que fiz no departamento. Obrigada pela amizade e apoio. Sem sombras de dúvida você é um dos grandes responsáveis por fazer as coisas funcionarem literalmente no departamento.

José Airton Oliveira, embora não esteja mais com a gente no departamento você me acompanhou desde a graduação e sua ajuda foi muito importante nos meus primeiros passos. Obrigada.

Paulo Eduardo Santos, você é o nosso mago das artes gráficas. Realmente é impressionante a sua habilidade com o desenho digital... Mas além disso, você é uma pessoa que admiro muito pelo seu jeito simples e amigo, sempre disposto a ajudar a todos. Obrigada, pois o toque artístico deste trabalho foi com toda certeza seu. 
Rosa Cristina Nogueira, Rosinha, você está sempre cuidando das "crianças" não é? Que sorte a nossa! Obrigada pelo carinho e dedicação de sempre. Sei que você também andou torcendo bastante por mim e a sua ajuda foi muito importante para que tudo desse certo.

Aos meus colegas da pós-graduação:

Foram realmente "Anos Incríveis" estes que passamos juntos. Não dá para expressar em poucas palavras minha gratidão pelo carinho e amizade. Vou me lembrar sempre do jeitinho de cada um e do quanto aprendemos juntos. Obrigada.

Gostaria também de fazer um agradecimento especial ao amigo e colega, Alessandro Dourado Loguércio pela participação importante que teve no desenvolvimento deste trabalho tanto na parte experimental como na sua revisão e discussão. Valeu mesmo, Alezinho. 


\section{SUMÁRIO}

p.

LISTA DE FIGURAS

LISTA DE TABELAS

LISTA DE ABREVIATURAS E SIGLAS

LISTA DE SÍMBOLOS

RESUMO

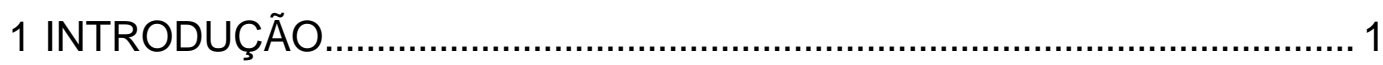

2 REVISÃO DA LITERATURA ............................................................... 3

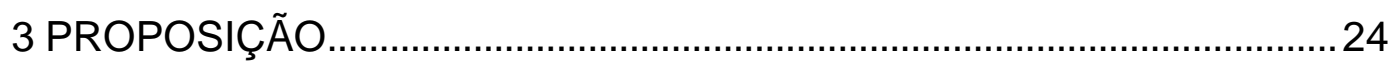

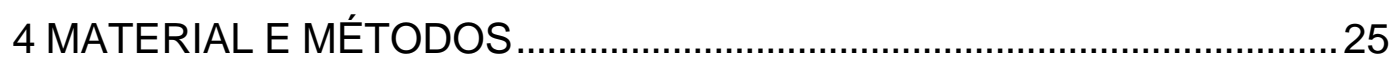

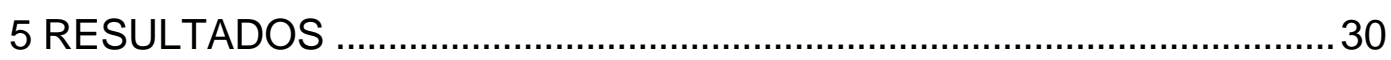

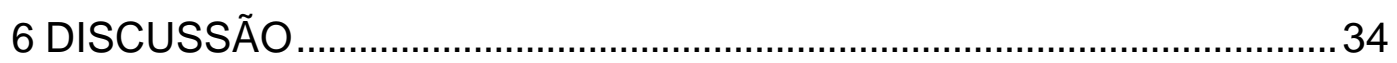

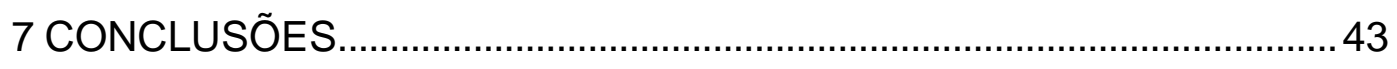

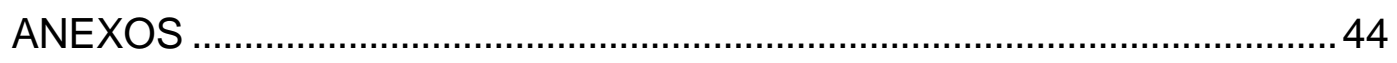

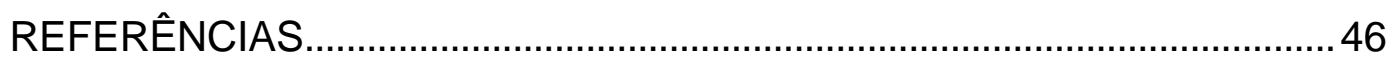

SUMMARY

APÊNDICE 


\section{LISTA DE FIGURAS}

Figura 4.1 - Dispositivo para preparos padronizados 25

Figura 4.2 - Preparo cavitário 25

Figura 4.3 - Esquema das 6 técnicas restauradoras aplicadas . .27

Figura 4.4 - Seções externas e internas .27

Figura 4.5 - Microdurômetro. 28

Figura 5.1 - Perfis médios da largura média de gaps. 31

Figura An. 1 - Contração de Polimerização (\%) conforme Watts \& Cash (1991) 44

Figura An. 2 - Intensidade de luz capaz de atravessar $1 \mathrm{~mm}$ da resina $\left(\mathrm{mW} / \mathrm{cm}^{2}\right)$ 45 


\section{LISTA DE TABELAS}

Quadro 4.1 - Material empregado no presente estudo. 26

Tabela 5.1 - Estatísticas descritivas para largura média do gap...... 30

Tabela 5.2 - Análise de variância para a largura média de gaps 32

Tabela 5.3 - Larguras médias dos gaps ( $\mathrm{Im}$ ) ajustados e intervalos de confiança $(95 \%)$ 33

Tabela An. 1 - Análise de variância da contração de polimerização 44

Tabela An. 2 - Comparações múltiplas de Tukey. 44

Tabela An. 3 - Análise de variância da intensidade de luz. 45

Tabela An. 4 - Comparações múltiplas de Tukey. 45 


\section{LISTA DE ABREVIATURAS E SIGLAS}

CP - Contração de polimerização

$\mathrm{RC}$ - Resina composta

ME - Módulo de elasticidade

QA - Quimicamente ativada

FA - Fotoativada

CIV - cimento de ionômero de vidro

CETL - coeficiente de expansão térmica linear

MEV - microscopia eletrônica de varredura

Z-v - combinação resina Z-250 e técnica vertical

Z-o - combinação resina Z-250 e técnica oblíqua 
Z-t - combinação resina Z-250 e técnica teste

D-v - combinação resina Durafill VS e técnica vertical

D-o - combinação resina Durafill VS e técnica oblíqua

D-t - combinação resina Durafill VS e técnica teste

$\mathrm{n}$ - número de repetições

c-comprimento do gap

I - largura do gap

Im - largura média do gap

$\mathrm{AgNO}_{3}$ - nitrato de prata

$\mathrm{GPa}$ - giga Pascal

$\mathrm{mm}$ - milímetro

$\mu \mathrm{m}$ - micrometro 


\section{RESUMO}

\section{ESTUDO DA INTERFACE ADESIVA EM RESTAURAÇÕES QUE COMBINAM RESINAS COM DIFERENTES MÓDULOS DE ELASTICIDADE}

O objetivo deste estudo foi o de avaliar uma técnica teste para inserção de resinas compostas combinadas e duas técnicas convencionais, quanto à qualidade da interface adesiva, em restaurações classe $\mathrm{V}$ realizadas em dentes bovinos. Foram utilizadas as resinas compostas (Z250 e Durafill VS) com o sistema adesivo (Single Bond) em 30 preparos confeccionados nas superfícies vestibulares dos dentes (fator $\mathrm{C}=3$ ). Portanto, foram analisadas seis técnicas restauradoras com 5 repetições: incremental vertical (Z-v e D-v), incremental oblíqua (Z-o e D-o), e teste [Z-t e D-t (forramento das paredes cavitárias com uma resina e preenchimento com a outra)]. Os espécimes foram armazenados por $24 \mathrm{~h}$ em água a $37^{\circ} \mathrm{C}$ e secionados no sentido V-L, originando 4 superfícies para obtenção de dados por espécime, as quais foram condicionadas (ácido fosfórico a 37\%, por 3s) e coradas (azul de metileno a $0,5 \%$, por 2 s). Para mensurar o comprimento (c) e a largura (I) dos gaps, a interface adesiva foi examinada por microscopia ótica (400x). A largura média $(\mu \mathrm{m})$ dos gaps foi calculada 
através da equação $\operatorname{Im}=\Sigma\left(c_{n} \times I_{n}\right) / \Sigma c_{n}$. Os resultados obtidos pelo tratamento estatístico dos dados (ANOVA para Medidas Repetidas) mostraram que somente a Técnica e a Superfície de leitura foram significativas $(p<0,05)$. Concluiu-se com base nestes resultados que a técnica teste apresentou qualidade de interface inferior, ou seja, gaps mais largos e que, a largura média dos gaps relativa àseção central foi maior que a das superfícies externas medidas. 


\section{INTRODUÇÃO}

O desenvolvimento dos sistemas adesivos e das resinas compostas ampliou as possibilidades restauradoras ao alcance do clínico. Contudo, as freqüentes formações de gaps na interface adesiva são ainda razão para preocupação clínica. Esta ocorrência pode levar a efeitos indesejáveis como a sensibilidade pós-operatória e a infiltração marginal comprometendo a longevidade das restaurações.

Alguns procedimentos clínicos foram propostos a fim de reduzir a possibilidade de falhas associadas à contração de polimerização. São exemplos as técnicas para inserção de resina composta e uso de bases para minimizar o efeito do fator- $C$, intensidade luminosa e modos de ativação para reduzir a velocidade da polimerização. É importante visualizar o conjunto de fatores e efeitos para que a adoção de manobras clínicas seja realizada de modo racional.

A interação do material restaurador com a estrutura dental através da técnica adesiva influencia a geração de tensões na restauração, assim como a contração de polimerização, o módulo de elasticidade e a cinética da reação de polimerização das resinas compostas. 
Ainda não se sabe qual a relevância de cada fator no conjunto, já que os resultados alcançados permanecem controvertíveis, mas estas características parecem estar vinculadas principalmente à formulação da resina composta.

A combinação de resinas com diferentes módulos de elasticidade pode ser uma forma eficaz para aliviar as tensões no sistema restaurador. $\mathrm{O}$ emprego de resinas do tipo flow tem alcançado resultados positivos, pois elas atuam na dissipação de tensões reduzindo a transmissão das mesmas para a interface adesiva.

No entanto, a influência da combinação de resinas compostas com módulos de elasticidade distintos ainda não está clara, uma vez que há diferenças marcantes de contração volumétrica entre as resinas flowe as de preenchimento da cavidade.

Considerando-se a importância do binômio contração de polimerização e módulo de elasticidade para definir a magnitude de tensões geradas na interface, buscou-se neste estudo avaliar a combinação desses fatores por meio da análise da interface de união, associando-a aos conhecimentos atuais ligados æ̀s técnicas restauradoras. 


\section{REVISÃO DA LITERATURA}

A contração de polimerização (CP) é uma característica intrínseca das resinas compostas $(\mathrm{RC})$ e sua relevância clínica se dá justamente pela sua interação com a estrutura dental através da adesão. Numa restauração ocorre competição entre as tensões de $\mathrm{CP}$ e a resistência de união às estruturas dentais. Quando a resistência de união supera as tensões de CP, ocorre falha coesiva no material restaurador, deflexão de cúspides, fratura no esmalte. Se as tensões de CP são maiores que a resistência de união, surgem gaps (fendas ou falhas) na interface adesiva. Tais efeitos podem comprometer a restauração causando sensibilidade pós-operatória e infiltração marginal, as quais poderão propiciar a recidiva de lesões de cárie.

No entanto, deve-se considerar que a reação de polimerização envolve tanto o desenvolvimento como o alívio das tensões. Nos estádios iniciais da polimerização, fase pré-gel, as cadeias poliméricas se formam de modo linear e possuem mobilidade, permitindo que as tensões induzidas pela CP sejam dissipadas através do escoamento. À medida que a reação progride, fase pós-gel, começam a se formar ligações cruzadas entre as cadeias dificultando o escoamento e, simultaneamente conferindo ganho nas 
propriedades mecânicas e no módulo de elasticidade (ME), que implica na indução de tensões na restauração. ${ }^{1}$

O relaxamento das tensões de polimerização foi aferido experimentalmente, mensurando-se as deformações do material, durante 45 min, com auxílio de uma célula de carga em tração. A diferença entre os cálculos teóricos da tensão de polimerização e os dados experimentais (muito menores que os previstos) permitiu concluir que realmente ocorreu relaxamento de tensões através do escoamento. ${ }^{2}$

Davidson, de Gee e Feilzer (1984) avaliaram resinas quimicamente ativadas (QA) e fotoativadas (FA) quanto às tensões de polimerização desenvolvidas na interface. Através de modelo linear e tridimensional de uma cavidade (classe V) foi possível observar que: no linear, a resistência de união superou as tensões de CP resultando em interfaces íntegras; no tridimensional, as interfaces apresentaram falhas evidenciadas pelo uso de corantes. Os autores concluíram que a forma da cavidade foi importante na manutenção da interface adesiva. ${ }^{3}$

Pensou-se então, que a interação do material restaurador com a estrutura dental era importante no desenvolvimento e alívio de tensões por definir o grau de restrição ao escoamento da resina, nas fases iniciais de polimerização.

Em 1987, Feilzer et al. elaboraram o conceito de fator de configuração cavitário (fator- $\mathrm{C}=$ área total aderida $\div$ área total livre). Para isso, estudaram as tensões de $\mathrm{CP}$ de duas resinas $\mathrm{QA}$ em diferentes fatores cavitários. Para fator- $C \leq 1$, as tensões de $C P$ foram menores que a resistência de união e a 
integridade da interface foi mantida. Contudo, para fator- $\mathrm{C}>2$, houve falhas coesivas nas RC já que os discos de aço utilizados receberam uma camada de silano indicando que em condições clínicas semelhantes poderiam ocorrer falhas na interface adesiva. ${ }^{4}$

Em 1990, os mesmos autores utilizaram a metodologia anterior para determinar quantitativamente a redução das tensões de contração pelo escoamento durante a polimerização. Para isto calcularam, de modo teórico, os valores das tensões desenvolvidas e subtraíram os valores conseguidos experimentalmente. $\mathrm{O}$ alívio de tensões pelo escoamento dependeu da RC considerada (diferentes ME e cinéticas da reação) e também do fator- $\mathrm{C}$. $\mathrm{O}$ escoamento contribuiu muito para o alívio das tensões quando o fator-C era 0,5 , mas foi insuficiente para um fator- $\mathrm{C} \geq 2 .^{5}$

Como no estudo de 1987 foram utilizadas apenas resinas QA, ${ }^{4}$ surgiu a dúvida quanto à influência do modo de ativação na capacidade de escoamento da RC. Para elucidar esse ponto foi desenvolvido um estudo semelhante, utilizando resinas $F A$, sobre a influência do fator- $C$ no escoamento. Em um dos grupos estas resinas foram espatuladas, a fim de incorporar porosidades como ocorre com as resinas QA. Os autores verificaram que as resinas FA geraram maiores tensões de CP do que o grupo das resinas $\mathrm{QA}$, sendo que estas últimas também resistiram melhor às tensões prematuras. Por outro lado, as FA escoaram menos que as QA e a incorporação de porosidade nas resinas FA diminuiu a velocidade da reação de polimerização e o desenvolvimento das tensões de contração. ${ }^{6}$ 
Entretanto, nos estudos citados a estrutura dental não foi utilizada como substrato para adesão, dificultando a extrapolação dos achados para situações clínicas. Assim, de forma concomitante, testes de infiltração marginal com corantes e análise da adaptação marginal, foram elaborados para avaliar os reais efeitos deletérios da CP.

Foi testada a hipótese de que tais efeitos poderiam ser reduzidos por meio de procedimentos restauradores ao alcance do clínico como: o uso de técnica incremental, a adição de inserts de vidro ou pequenas porções de resina pré-polimerizada, e a utilização de um material com ME baixo situado entre a dentina e a RC. ${ }^{7}$

Numa revisão da literatura sobre estudos com o teste de infiltração marginal, Gale \& Darvell (1999) analisaram o emprego de ciclos térmicos. O número de ciclos apresentou valores muito amplos (média de 10.000, mediana de 500 ciclos); a temperatura dos banhos foi mais restrita $\left(6,6^{\circ} \mathrm{C}\right.$ no mínimo e $55,5^{\circ} \mathrm{C}$ no máximo), porém, o tempo de imersão também variou muito (média de 53s e mediana de 30s). Observaram também o uso de diferentes corantes como o azul de metileno, a fucsina básica, o nitrato de prata $\left(\mathrm{AgNO}_{3}\right)$, e o modo pelo qual eram empregados nos espécimes. Segundo os autores estas constatações limitariam comparações entre os resultados dos estudos, fato este agravado pela ausência de grupo controle imediato na grande maioria deles. ${ }^{8}$

Algumas concepções, como o uso de incrementos para reduzir o volume de resina a sofrer contração e a contração das resinas em direção à luz, nortearam o desenvolvimento de muitas técnicas para inserir o material. 
Com estes preceitos em voga, foram criadas as cunhas reflexivas. ${ }^{9}$ Em cavidades MOD, forradas ou não com cimento de ionômero de vidro, a $\mathrm{RC}$ foi inserida e ativada (com auxílio de cunhas reflexivas) na caixa proximal em três incrementos ( $\mathrm{G}, \mathrm{V}$ e $\mathrm{L})$. Os espécimes foram submetidos a ensaios de envelhecimento e teste de infiltração marginal. No grupo com CIV a porcentagem de margens excelentes foi maior mesmo após ciclos térmicos e de carga, fato este atribuído àredução do volume de $\mathrm{RC}$ e das superfícies aderidas (menor fator-C efetivo), aliado à utilização de um material com propriedades físicas semelhantes àdentina. ${ }^{10}$

A partir de então, alguns estudos compararam a técnica para inserção em bloco único com várias técnicas de múltiplos incrementos. Entre eles está o de Fisbein et al. (1987) com incrementos G-O, ${ }^{11}$ o de Leclaire et al. (1988) com dois incrementos oblíquos (O e G), ${ }^{12}$ o de Koenigsberg et al. (1989) com incrementos G-O e V-L. ${ }^{13}$ Os resultados obtidos pela análise da infiltração marginal se mostraram mais favoráveis æ̀ técnicas incrementais.

Contudo, ora as margens das restaurações se apresentavam totalmente em esmalte, ${ }^{11}$ ora a técnica restauradora incorporava o uso de hidróxido de cálcio como base, 12, 13 impossibilitando avaliar o efeito exclusivo da técnica para inserção.

Como a base de hidróxido de cálcio se destacava da parede cavitária, ${ }^{13}$ Donly et al. (1990) elaboraram um estudo comparativo de técnicas restauradoras com diferentes bases, CIV ou hidróxido de cálcio, e modos de inserção (bloco único ou incrementos V-L). Os espécimes foram submetidos a ciclos térmicos e mecânicos, imersos em solução a $50 \%$ de 
$\mathrm{AgNO}_{3}$ e avaliados quanto ao grau de infiltração. Os autores concluíram que houve menor penetração do corante quando o CIV foi usado como base. ${ }^{14}$

No entanto, nota-se que no delineamento experimental as restaurações com CIV foram todas restauradas com técnica incremental e as com hidróxido de cálcio em bloco único, de modo que não se pode atribuir os resultados positivos encontrados, exclusivamente ao uso da base de CIV.

O uso do CIV associado à técnica para inserção continuou sendo objeto de estudo em outra pesquisa, em que quatro grupos foram comparados quanto à infiltração marginal (bloco único, incrementos G-O, incrementos oblíquos na proximal e único na oclusal com ou sem base). Os menores graus de infiltração foram similares na técnica de bloco único e de incrementos oblíquos sem base, sendo que na primeira a diminuição de tensões na gengival seria decorrente da atenuação da luz. Não foi visto efeito favorável no emprego do CIV, talvez pela ausência do condicionamento da dentina. ${ }^{15}$

Em 1997, também foram comparadas técnicas restauradoras (bloco único x múltiplos incrementos $\mathrm{x}$ técnica indireta) e bases (adesivo $\mathrm{x}$ CIV $\mathrm{x}$ cimento de fosfato de zinco) em preparos classe I. Durante a polimerização (30 min) foi mensurado o deslocamento do menisco de um líquido numa pipeta acoplada ao dente por conexões hidráulicas e, o volume referente aos gaps de cada restauração estimado. Observou-se que os espécimes tratados com o adesivo apresentaram os menores volumes de gaps, seguidos pelos do CIV e por último os do fosfato de zinco. De modo geral, os 
gaps foram menores na técnica de incrementos e na das restaurações indiretas. $^{16}$

No entanto, deve-se analisar essa metodologia com mais cuidado. Há limitações principalmente relacionadas a fenômenos de sorção, e à impossibilidade de se atribuir os deslocamentos hídricos observados exclusivamente aos gaps. Foi relatada a presença de fendas tanto na estrutura dental como no material restaurador, também decorrentes da polimerização. ${ }^{16}$

Em 1992, foram comparadas técnicas restauradoras utilizando como variável resposta a largura média dos gaps, medidos em 5 posições na parede gengival de restaurações classe II. As técnicas escolhidas foram: inserção em bloco e ativação única, bloco e 3 tempos de ativação ( $V, L$ e O), 3 incrementos G-O, 3 incrementos oblíquos V-L-O e 3 incrementos V-L-G, sendo o primeiro paralelo àgengival. Não houve diferença significativa entre as técnicas testadas, exceto para a de incremento único e 3 tempos de ativação que originou gaps mais largos. Nota-se que sem a utilização de base não houve vantagem da técnica por incremento sobre a de bloco único com única ativação. ${ }^{17}$

Resultados semelhantes foram apresentados por um outro estudo comparativo de técnicas para inserção (bloco único, incrementos paralelos æ̀ paredes cavitárias e incrementos diagonais) associadas ao desenho da cavidade (classe II). O autor concluiu que a infiltração marginal não depende do desenho cavitário, nem da técnica de inserção. O resultado foi atribuído à falta de direcionamento dos vetores de CP pela fonte de luz. ${ }^{18}$ 
Com o mesmo raciocínio usado para a técnica incremental, reduzir o volume do material a sofrer contração, foi proposto o uso de porções prépolimerizadas de RC ou inserts (vidro ou cerâmica).

Foram comparadas várias técnicas para inserção de $\mathrm{RC}$, quanto à infiltração marginal, em cavidades classe II: bloco único, incrementos horizontais, incrementos verticais, e com porções esféricas prépolimerizadas adicionadas ao material. Os espécimes foram envelhecidos e, após a imersão em corante analisou-se o grau de penetração do mesmo. Os resultados permitiram ao autor concluir que a técnica vertical foi significativamente superior æ̀s demais, e que não houve diferença entre as outras. ${ }^{19}$

Em 1996, a técnica da RC pré-polimerizada ou inserts de $\beta$-quartzo foi comparada à de bloco único, quanto à infiltração marginal. Após os procedimentos usuais (ciclos térmicos, imersão em corante e leitura do grau de infiltração) a análise dos dados demonstrou que a técnica para inserção de porções pré-polimerizadas apresentou maior infiltração e, que não houve diferença entre as demais. O menor grau de infiltração dos inserts de $\beta$ quartzo foi atribuído à semelhança de seu coeficiente de expansão térmica linear (CETL) com o da dentina. Os piores resultados podem ter sido ocasionados pelo maior CETL das porções pré-polimerizadas (cerca de 3x) ou pelo volume insuficiente do insert (não reduziu significativamente o volume de resina na polimerização). ${ }^{20}$

Avaliou-se o desempenho de restaurações classe II de RC, por meio da infiltração marginal, em função do material restaurador, do sistema 
adesivo, da técnica para inserção (bloco único ou incrementos G-O) e da intensidade luminosa. Os melhores resultados foram alcançados com o uso de inserts de porcelana. O material restaurador foi o fator preponderante nos resultados obtidos e a influência dos adesivos foi semelhante entre eles. A fonte de luz e a técnica para inserção influíram de forma diferente nas $\mathrm{RC}$ empregadas. $^{21}$

Buscando uma explicação para os resultados contrastantes envolvendo o uso de técnica em incrementos e de inserts surgiram muitos estudos empregando o método dos elementos finitos e o fotoelástico.

Num estudo pelo método dos elementos finitos foram modeladas quatro técnicas para inserção: em bloco único, em incrementos V-L e G-O, oblíqua, e oblíqua com formato em U. Cada incremento foi considerado completamente polimerizado antes da inserção do seguinte. As técnicas com vários incrementos causaram maior acúmulo de tensões do que a de bloco único. Este fato foi atribuído à deformação da cavidade provocada pela CP que a cada incremento reduzia o volume da cavidade, de modo que ao final, o volume de resina inserido era menor que o volume original da cavidade provocando maior tensão na interface. As técnicas para inserção oblíquas apresentaram concentrações de tensões mais severas ao longo da interface. 22

Resultados semelhantes foram apresentados em outro estudo. Foram modeladas as técnicas para inserção de RC em cavidades classe V: bloco único, incrementos G-O, e incrementos oblíquos. Observou-se que as maiores tensões ocorriam antes da polimerização ter se completado, 
conforme verificado anteriormente. ${ }^{23} \mathrm{~A}$ inserção em bloco apresentou as menores tensões transitórias, tanto em esmalte como em dentina, e a de incrementos oblíquos os maiores picos de tensões de cisalhamento. ${ }^{24}$

Estes achados foram confirmados também por um terceiro estudo (método fotoelástico) que avaliou as técnicas para inserção em bloco único, em bloco modificado (um bloco para a caixa proximal e um para a caixa oclusal), e em incrementos oblíquos G-O e V-L. As em bloco (único e modificado) apresentaram as menores tensões de CP e a oblíqua as maiores. ${ }^{25}$

Baseando-se nos estudos citados, a hipótese de que uma técnica para inserção do material em incrementos reduziria as tensões da CP estaria rejeitada, não mais servindo como justificativa para seu emprego. Assim, ao que tudo indica o uso de técnica incremental parece estar mais vinculado ao grau de conversão na resina.

Entretanto, é importante considerar limitações no emprego do método de elementos finitos, pois a presença de gaps não foi normalmente prevista. Neste método é assumida a existência de uma interface adesiva perfeita.

A hipótese que pequenas falhas poderiam levar a grandes tensões na interface e causar uma falha completa, foi analisada por elementos finitos. Os autores modelaram uma restauração (classe V) em premolar simulando a aplicação de carga oclusal de 100 N. Os picos das tensões de tração e de cisalhamento na interface aumentaram cerca de 5 vezes quando havia falhas na interface, confirmando a hipótese dos autores. ${ }^{26}$ 
Em face destes conhecimentos, as atenções se voltaram para um procedimento comum que em algumas situações favoreceu a integridade marginal e que poderia ser um fator relevante para redução das tensões de CP: a fotoativação.

O pressuposto que os vetores das forças de CP ocorriam em direção à luz baseava-se no consenso que as camadas de resina mais próximas à fonte de luz se polimerizam primeiro, e assim sucessivamente em profundidade. Como os vetores de contração ocorreriam de forma análoga, o direcionamento da fonte luminosa favoreceria a preservação da interface.

Entretanto, Versluis et al. (1998) empregaram os elementos finitos para observar a direção de $\mathrm{CP}$ das resinas. Simularam um modelo, tanto para a resina QA como para a FA, com incidência de luz a $90^{\circ}$ ou $45^{\circ}$, através de cunhas reflexivas, nas condições de adesão perfeita æ̀̀ paredes cavitárias ou somente em esmalte ou sem adesão æ̀ paredes cavitárias. Os resultados demonstraram que os vetores de $\mathrm{CP}$ não são afetados significativamente pela direção da luz aplicada, e sim pelas superfícies aderidas, de modo que seriam importantes o formato da cavidade e a qualidade de adesão. ${ }^{27}$ Esta assertiva corrobora os achados de Feilzer et al., $1987 .{ }^{4}$

Resultados semelhantes foram apresentados em 1999 por Kinomoto et al., ${ }^{28}$ ao compararem a CP de uma resina experimental QA àde uma FA, por meio do método fotoelástico. O padrão de distribuição de tensões foi semelhante. Contudo, as tensões geradas pela FA foram superiores à da QA, aspecto este já enfocado anteriormente pela literatura. ${ }^{6} \mathrm{~A}$ cinética de 
polimerização pode ser o fator mais importante na magnitude de tensões internas, para os autores.

Com base nestes achados, pensou-se que os bons resultados encontrados em estudos anteriores atribuídos ao direcionamento da CP em direção a luz, como os de Segura et al. (1992) em que se verificou menor largura de gaps em dentina quando a fotoativação foi realizada através da estrutura dental, poderiam ser explicados pela atenuação da intensidade de luz. ${ }^{29}$

O efeito da atenuação da intensidade de luz pela estrutura dental foi avaliado em um estudo que observou redução em torno de $42 \%$ da profundidade de polimerização com a interposição de uma faceta de esmalte (1,6mm de espessura) e em aproximadamente $16 \%$ no valor de dureza Rockwell sendo que estes resultados variaram conforme o tipo de resina considerada. ${ }^{30}$

A própria cunha reflexiva utilizada em estudos como os de Lutz et al. (1986) ${ }^{9,10}$ promove redução da intensidade de luz transmitida conforme verificado pelos autores. Segundo de Goes (1992), essa atenuação pode alcançar uma diminuição de $83,9 \%$ já que menos de $8 \%$ da intensidade original da fonte de luz era transmitida por ela. ${ }^{31}$

Então se pensou que na realidade, através da estrutura dental a intensidade luminosa seria atenuada e a velocidade de reação de polimerização reduzida, facilitando desta forma o escoamento e conseqüente alívio das tensões acumuladas propiciando a manutenção da interface adesiva. 
Esta hipótese está de acordo com o estudo de Lösche (1999) que comparou para duas intensidades de luz (baixa e alta) a técnica de Lutz e a de fotoativação por oclusal, utilizando o método de análise quantitativa de margens (microscopia eletrônica de varredura - MEV - 200x). Apenas a intensidade de luz foi significativa: mantendo-se as intensidades de luz semelhantes dentro da cavidade, foi indiferente a forma de fotoativação (“direcionada" por V, L e C ou O). ${ }^{32}$ Contudo, neste estudo utilizou-se base de CIV e as margens das restaurações foram todas em esmalte.

Anteriormente foi estudada a influência da intensidade de luz (250 ou $450 \mathrm{~mW} / \mathrm{cm}^{2}$ ) sobre: $\mathrm{CP}$, dureza, resistência à flexão, $\mathrm{ME}$ e adaptação marginal. Utilizou-se o método de análise quantitativa de margens e foi elaborado um índice marginal ( $\mathrm{IM}=$ comprimento do gap $\times$ largura $\left.\times 10^{-2}\right)$. Com relação àqualidade da interface avaliada ao microscópio eletrônico de varredura (MEV), os gaps apresentaram médias bem diferentes $(7,5 \mu \mathrm{m}$ e 15,4 $\mu \mathrm{m})$. A intensidade mais alta causou interface de pior qualidade para uma das RC, fato este atribuído às diferenças de $\mathrm{ME}$, pois os valores de $\mathrm{CP}$ foram semelhantes. ${ }^{33}$

A influência da intensidade luminosa (250 ou $650 \mathrm{~mW} / \mathrm{cm}^{2}$ ) na CP e na integridade da interface (MEV) foi estudada em técnica restauradora envolvendo ou não a utilização de uma resina do tipo flow. Após o uso de ciclos térmicos foi realizada a análise quantitativa de margens, onde não se observou efeito significativo da técnica restauradora. Mas, as restaurações ativadas com a intensidade menor apresentaram menos defeitos de interface, fato este atribuído àredução na velocidade da polimerização. ${ }^{34}$ 
Quando diferentes intensidades de luz $(50,180,450,600$ e $800 \mathrm{~mW} / \mathrm{cm}^{2}$ ) foram relacionadas aos graus de infiltração marginal, encontrou-se resultado similar ao anteriormente descrito. A diferença só foi significativa entre a menor e a maior intensidade, sendo que a infiltração aumentou na mesma seqüência. ${ }^{35}$

Com base no pressuposto que reduzindo a velocidade da reação se pode conseguir melhor adaptação marginal, foi proposta a fotoativação gradual (4 min até atingir a máxima intensidade). Ao se comparar a convencional com a gradual, quanto à qualidade da interface (MEV), a primeira permitiu a detecção de áreas com gaps na dentina e, a segunda propiciou margens contínuas, consideradas excelentes, em toda interface. ${ }^{36}$

Este estudo foi desenvolvido na busca da melhor combinação entre tempo de ativação (10 e 60s) e intensidade de luz (175 e $\left.700 \mathrm{~mW} / \mathrm{cm}^{2}\right)$ para resina híbrida e de micropartículas com diferentes cores, quanto à $\mathrm{CP}$, dureza Brinnel e qualidade da interface (MEV). Verificou-se que a redução na intensidade de luz diminuiu a velocidade da reação, mas não afetou o grau de conversão desde que utilizados 60 s de exposição. De modo geral, a cor das RC empregadas não influenciou nos valores de dureza obtidos, provavelmente devido à fina espessura utilizada. Por outro lado, as diferentes RC apresentaram a qualidade de suas interfaces afetadas de modo distinto, pela intensidade de luz e tempo de exposição, para a mesma cor inclusive. ${ }^{37}$

A obtenção de uma melhor interface adesiva não é desejável se conseguida em detrimento do grau de conversão, que está relacionado æ̀s 
propriedades mecânicas da RC e é importante para o bom desempenho clínico do material.

Assim, o efeito da atenuação em decorrência da cor voltou a ser abordado num estudo comparativo entre o método convencional $\left(500 \mathrm{~mW} / \mathrm{cm}^{2}\right)$ e o de ativação com LASER de XeCl no modo pulsado. Foram utilizadas RC nas cores clara e escura e avaliados o grau de conversão e a CP em espécimes com 1, 2 e 3mm de espessura. A cor e a profundidade da polimerização não foram afetadas nos espécimes ativados com o LASER; eles também apresentaram maior grau de conversão e menor CP. Com a fotoativação convencional, as cores claras apresentaram maior grau de conversão, porém houve redução significativa em função da profundidade de polimerização, sendo mais pronunciado nas cores escuras. ${ }^{38}$

Procurando alcançar um grau de conversão ótimo e ao mesmo tempo conseguir o alívio das tensões da CP, a fim de manter a integridade marginal, a ativação convencional contínua foi comparada com a ativação em dois tempos. Foram avaliadas as durezas superficiais, adesão, CP, viscosidade e monômeros residuais, em onze protocolos de ativação com dose total de energia diferente. Os autores concluíram que a ativação em dois tempos promove valores semelhantes de $\mathrm{CP}$ total, dureza e monômero residual, desde que seja fornecida uma dose de energia total mínima correspondente a $17000 \mathrm{mWs} / \mathrm{cm}^{2}$, mas os valores de adesão podem ser melhorados por esta técnica. ${ }^{39}$ Contudo, estes resultados precisariam ser avaliados em condições clínicas, já que para o teste de adesão utilizou-se uma superfície de aço inoxidável como substrato. 
O conceito "dose de energia total" prevê que a polimerização da RC está relacionada ao total de energia fornecido a ela e não ao modo como esta foi fornecida. É obtida pelo produto da intensidade de luz do fotoativador $\left(\mathrm{mW} / \mathrm{cm}^{2}\right)$ e do tempo de exposição (s). ${ }^{40}$

Este conceito norteou a proposição de uma técnica de retardo do pulso em que é feita uma primeira ativação, com baixa intensidade de luz por 3s $\left(200 \mathrm{~mW} / \mathrm{cm}^{2}\right)$ e, há uma espera de 3 a $5 \mathrm{~min}$, quando a resina pode ser acabada e polida. A polimerização final será alcançada pela exposição do material à alta intensidade luminosa $\left(500 \mathrm{~mW} / \mathrm{cm}^{2}\right)$ pelo tempo indicado pelo fabricante. Esta técnica foi testada em diferentes $\mathrm{RC}$ e comparada à ativação contínua convencional, quanto a deformação provocada pela CP, com o auxílio de uma célula de carga. A deformação encontrada foi reduzida de $4 \%$ a $34 \%$ dependendo da resina testada. Concluiu-se que a técnica proposta apresenta efeitos benéficos com relação æ̀s tensões residuais da restauração. ${ }^{1}$

Procurando elucidar a questão, Christensen et al. (1999) avaliaram 14 tipos de aparelhos fotoativadores, incluindo os de LASER-Ar, arco de plasma, luz halógena, com diferentes modos de aplicação de luz em diferentes tempos. Utilizou-se seis marcas comerciais de $\mathrm{RC}$ nas quais foram observadas a CP, ME, geração de calor no dente, deformações causadas pela CP, alterações físicas no dente e no material restaurador durante os testes. O modo de fotoativação não foi significativo. Não houve redução significativa da CP com diferentes combinações de intensidades e tempos de ativação; também não foi possível evitar as trincas no esmalte 
adjacentes às margens das restaurações. Os resultados foram bem indicativos e permitiram concluir que o fator relevante quanto aos problemas causados pela CP seria a formulação das RC. ${ }^{41}$

Apesar dos diferentes modos de fotoativação que procuram diminuir a velocidade da reação, reduzindo as tensões transmitidas à interface, terem mostrado seus efeitos benéficos, permanece a dúvida quanto ao fator que seria de fato relevante no desenvolvimento dessas tensões. Como nem todas as resinas são sensíveis, da mesma forma, a modificações no modo de ativação, a composição da RC ou o modo de ativação são dois possíveis candidatos ao título de fator de maior relevância.

De fato, a composição influi consideravelmente nas propriedades mecânicas das RC o que motivou uma classificação proposta por Willems et al. (1992) com base nas características morfológicas (tamanho médio de partículas, forma, distribuição e conteúdo de carga) e propriedades mecânicas (módulo de Young, rugosidade superficial, resistência à compressão, dureza superficial), a fim de facilitar critérios para seleção do material conforme a condição clínica. ${ }^{42}$

Observou-se num estudo que utilizou o método da nanoindentação que há diferenças de $\mathrm{ME}$ da dentina rígida até a restauração de $\mathrm{RC}$ que passa por uma zona de interdifusão e camada adesiva com menor ME. Este gradiente é tanto maior quanto mais espessa a camada de adesivo ou quando uma resina do tipo flowé utilizada. ${ }^{43}$

Estas observações apóiam o conceito de "paredes elásticas", segundo o qual as tensões de CP da resina de preenchimento da cavidade 
podem ser absorvidas por uma camada inicial relativamente elástica, preservando a interface. ${ }^{44}$

Este conceito aparentemente foi imaginado a partir dos estudos de Kemp-Scholte \& Davidson (1990) ${ }^{45,46}$ em que o uso de forramentos flexíveis aplicados entre o adesivo e a resina de preenchimento foi mais efetivo na preservação da interface (avaliada ao MEV) resultando num alívio de tensões de CP entre 20 e 50\% conforme o material intermediário. Como não houve correlação entre a resistência de união e a qualidade da interface, os bons resultados conseguidos foram atribuídos a uma diminuição da rigidez da restauração que se tornou suficientemente flexível para compensar parte das tensões de CP.

Considerando que a composição das $\mathrm{RC}$ se reflete em suas propriedades mecânicas, é importante relacioná-la àCP para se pensar nas conseqüências clínicas dessa relação. Com este objetivo, Labella et al. (1999) estudaram a CP, o ME e a cinética da reação em adesivos (com e sem carga) e resinas (flowe não). As resinas tipo flow apresentaram maior $\mathrm{CP}$ que as demais. O ME foi maior nas híbridas, intermediário nas flow, e menor na de micropartículas (Durafill VS). A cinética da reação variou conforme a RC. A resina Durafill VS apresentou baixa CP (provavelmente devido à incorporação de fragmentos do polímero na $\mathrm{RC}$ ) e baixa rigidez, uma combinação que pode ser menos prejudicial àinterface. ${ }^{47}$

Segundo Versluis \& Tantbirojn (1999) as tensões oriundas da CP não dependem unicamente da magnitude desta contração, mas também do ME e da velocidade com que ele se desenvolve com a polimerização. ${ }^{48}$ 
Um ME semelhante ao da estrutura dental (alto) seria mais favorável na manutenção da interface adesiva ao longo do tempo, pois minimiza deformações causadas pela fadiga relacionada æ̀s cargas oclusais. Contudo, um alto ME é também potencialmente danoso àinterface por gerar tensões de CP superiores, que pode ser contornado ao se combinar resinas com diferentes ME.

A hipótese que uma camada de resina sem carga mais espessa reduziria as tensões na interface adesiva também foi analisada por elementos finitos. Foram modeladas camadas da resina com 20 a $80 \mu \mathrm{m}$ de espessura, considerando-se um ME de 5 GPa para a resina sem carga e de 20 GPa para a resina de preenchimento. As tensões máximas de cisalhamento diminuíram com o aumento da espessura da resina sem carga, e as maiores tensões foram concentradas nos ângulos da restauração. Houve um decréscimo de até $38 \%$ na geração de tensões, quando se comparou com uma restauração efetuada sem o uso da resina sem carga. ${ }^{49}$

O efeito de espessuras diferentes de adesivo (20 a $300 \mu \mathrm{m}$ ) nas tensões de CP também foi analisado experimentalmente. As tensões foram medidas com o auxílio de uma célula de carga (fator- $C=2$ e 3), e a integridade marginal pela infiltração de $\mathrm{AgNO}_{3}$. A penetração do corante foi reduzida com o uso de camadas espessas de adesivo. Contudo, a espessura ideal a ser usada para se obter o efeito de amortecedor, é muito difícil em condições clínicas. ${ }^{50}$

O efeito de uma resina flow na interface de espécimes submetidos a ciclos térmicos foi avaliado ao MEV. A porcentagem de gaps foi calculada e 
segundo o autor, a utilização da resina flow foi eficaz na obtenção de interface resina-dentina íntegra $(p<0,05)$, mas não pôde prevenir a formação de trincas na interface com o esmalte. Entretanto, como o delineamento do estudo não considerou um grupo imediato, não é possível afirmar com absoluta certeza se os gaps encontrados foram resultantes da $\mathrm{CP}$, do envelhecimento dos espécimes, ou de ambos. ${ }^{51}$

Resinas flowe camadas mais espessas de adesivo com e sem carga também foram submetidos a microtração e os espécimes avaliados ao MEV. Os tipos de falha foram classificados em: tipo 1- falha adesiva entre o adesivo e a dentina e parcialmente coesiva no adesivo; tipo 2 - falha coesiva total no adesivo; tipo 3 - falha coesiva parcial em dentina e tipo 4 - falha coesiva na camada de compósito com baixa viscosidade. Não houve diferença entre os grupos testados quanto aos valores de adesão, mas houve diferença quanto ao tipo de falha: o uso de resina flowproporcionou uma redução drástica na falha de tipo 3 mais favorável à preservação da interface adesiva. $^{52}$

Contudo, as resinas do tipo flow usualmente devem seu alto escoamento àdiminuição do conteúdo de carga, o que implica em alta $\mathrm{CP}$, conforme demonstrado por Labella et al. (1999). ${ }^{47}$ Como as tensões geradas pela CP não dependem apenas do grau de contração volumétrica existentes, mas também do $\mathrm{ME}$ da resina, deve ter havido uma compensação o que explica os resultados favoráveis obtidos.

Entretanto, o desempenho clínico de uma restauração está relacionado com uma combinação em que os $\mathrm{ME}$ do material restaurador e 
da estrutura dental se assemelham. Se a discrepância entre os ME for muito grande, isto poderá resultar em tensões na interface adesiva, causada tanto por alterações térmicas quanto mecânicas, quando em função na cavidade bucal. ${ }^{53}$

Compreende-se que resinas com ME diferentes e mesmo grau de CP podem induzir tensões de magnitudes distintas na interface, o que ainda não foi explorado, pois, usualmente as resinas do tipo flowpossuem alta CP e as resinas a elas associadas como preenchimento apresentam baixa $\mathrm{CP}$, porém alto ME.

Assim, o efeito da combinação de resinas de diferentes ME com o intuito de diminuir as tensões na interface adesiva permanece não totalmente esclarecido, apesar da importância do ME nas tensões da CP e de sua associação aos novos conceitos relacionados às técnicas restauradoras. 


\section{PROPOSIÇÃO}

O objetivo deste estudo é testar a hipótese que a combinação de resinas com diferentes módulos de elasticidade e mesma contração de polimerização é favorável àqualidade da interface. 


\section{MATERIAL E MÉTODO}

Foram utilizados neste estudo 30 incisivos bovinos que tiveram suas raízes raspadas a fim de remover restos teciduais. Após a obtenção, os dentes foram conservados em solução de cloramina a 1\% e armazenados a $7^{0} \mathrm{C}$ até a fase inicial do experimento.

Com auxílio de um dispositivo mecânico (Fig. 4.1) e ponta de diamante 1095 em alta rotação foram realizados preparos cavitários padronizados do tipo classe $\mathrm{V}$ com as dimensões de $4 \mathrm{~mm}$ (altura) por $4 \mathrm{~mm}$ (largura) por $2 \mathrm{~mm}$ (profundidade) $\pm 0,2 \mathrm{~mm}$, com fator-C de 3. A margem gengival situava-se no limite amelocementário e o preparo apresentava ângulo cavo-superficial em $90^{\circ}$. (Fig. 4.2) $\mathrm{O}$ acabamento foi feito com a
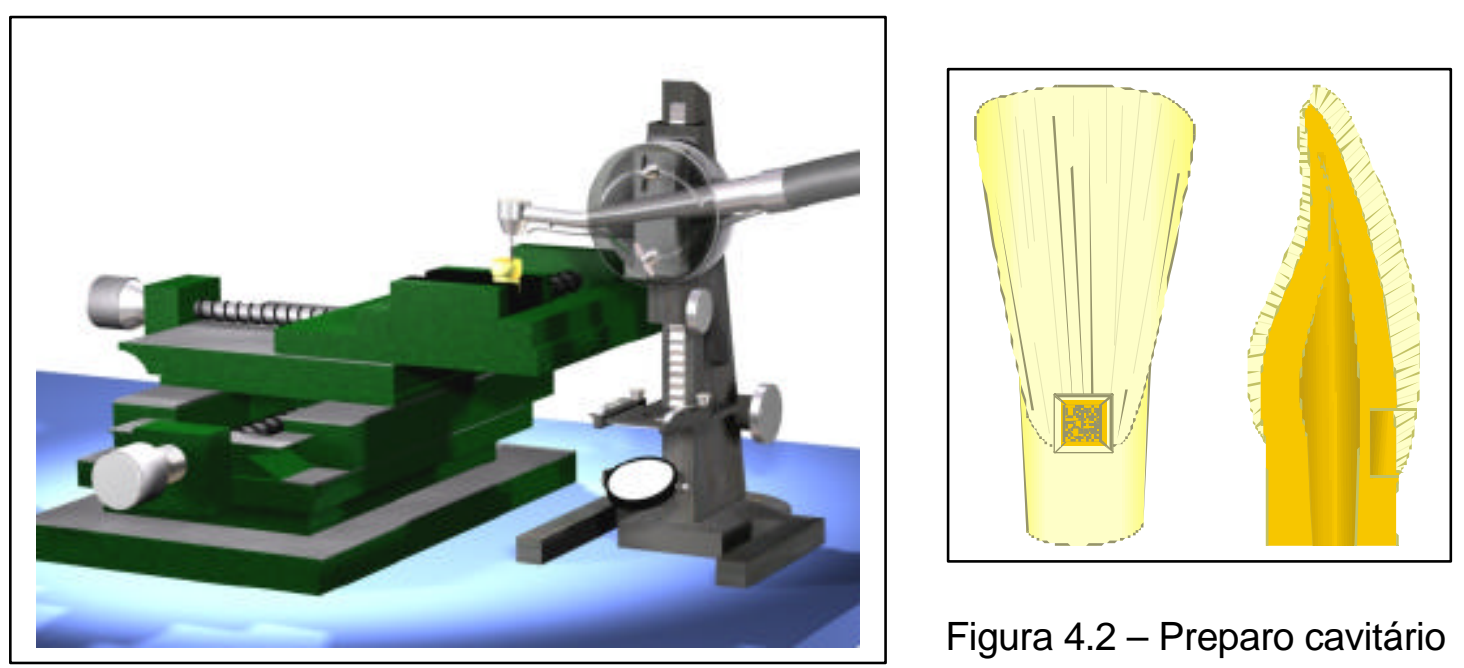

Figura 4.2 - Preparo cavitário

Figura 4.1 - Dispositivo para preparos padronizados 
própria ponta de diamante em baixa rotação e as medidas conferidas com paquímetro digital. Após remoção do terço incisal da coroa e 2/3 da raiz, foi realizada profilaxia com pedra pomes, os espécimes foram deixados durante 12 min num aparelho de ultra-som e, mantidos em água destilada até o momento da restauração.

Para este estudo foram escolhidas resinas com diferentes módulos de elasticidade e mesma contração de polimerização. Vide quadro abaixo.

Quadro 4.1- Material empregado no presente estudo

\begin{tabular}{|c|c|c|c|c|c|}
\hline Marca & Composição & ME (GPa) & CP (\%) & Fabricante & Lote \\
\hline $\begin{array}{c}\text { Z-250 } \\
(\operatorname{cor} A-3)\end{array}$ & $\begin{array}{c}\text { Partículas de carga: } \\
\text { zircônia/sílica }(60 \% \text { em } \\
\text { volume: } 0,19-3,3 \mu \mathrm{m}) \\
\text { Matriz: BIS-GMA, UDMA e } \\
\text { BIS-EMA }\end{array}$ & $14,1^{*}$ & $1,92^{\star * \star}$ & $3 \mathrm{M}$ & 1370A3 \\
\hline $\begin{array}{c}\text { Durafil } \\
\text { VS } \\
\text { (cor A- } \\
3.5)\end{array}$ & $\begin{array}{c}\text { Partículas de carga: dióxido } \\
\text { de silício }(0,02-0,07 \mu \mathrm{m}) \mathrm{e} \\
\text { fragmentos do polímero }(10- \\
20 \mu \mathrm{m}) \\
\text { Matriz: UDMA }\end{array}$ & $6,5^{\star *}$ & $1,92^{\star * *}$ & $\begin{array}{l}\text { Heraeus } \\
\text { Kulzer }\end{array}$ & 030123 \\
\hline $\begin{array}{l}\text { Single } \\
\text { Bond }\end{array}$ & $\begin{array}{l}\text { HEMA, BIS-GMA, água, } \\
\text { etanol, dimetacrilato, } \\
\text { fotoiniciador, ácido } \\
\text { polialcenóico, ácido } \\
\text { politacônico }\end{array}$ & - & - & $3 \mathrm{M}$ & OEL1105 \\
\hline
\end{tabular}

Foi feito condicionamento da cavidade com ácido fosfórico a 37\% por 15s. Após a lavagem foi efetuada a secagem com papel absorvente, buscando manter a superfície visualmente úmida, e aplicado o adesivo conforme as recomendações do fabricante. 
Numa seqüência aleatória os dentes foram restaurados com o auxílio de uma seringa Centrix de acordo com uma das 3 técnicas para inserção (Fig. 4.3) totalizando 6 condições experimentais $(n=5)$ : incremental vertical (Z-v e D-v), incremental oblíqua (Z-o e D-o) e teste [Z-t e D-t (forramento das paredes cavitárias com uma resina e preenchimento com a outra)]. Foi utilizado o fotoativador VIP (Bisco) com intensidade luminosa de $600 \mathrm{~mW} / \mathrm{cm}^{2}$ $(2 \times 40 s)$.
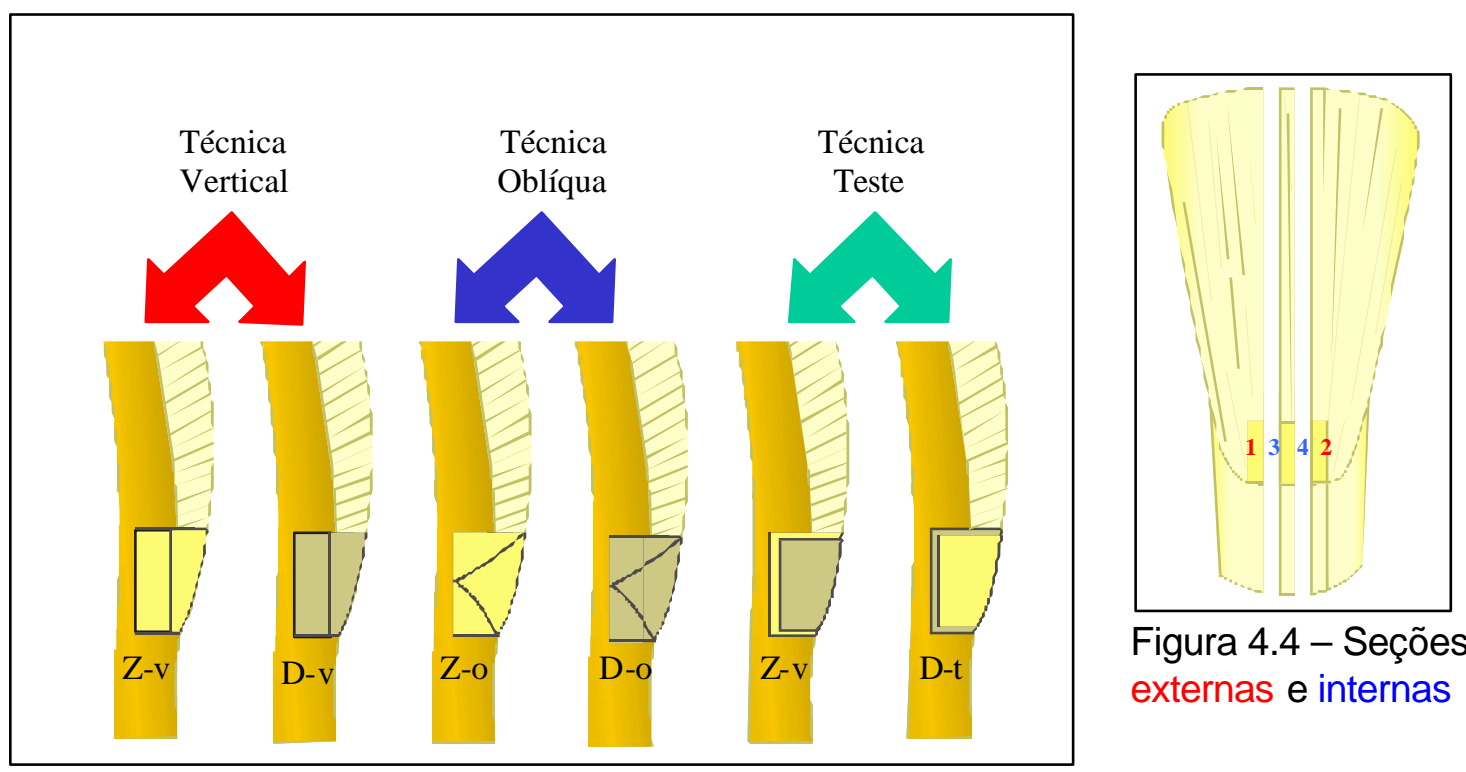

Figura 4.4 - Seções externas e internas

Fiqura 4.3 - Esquema das 6 técnicas restauradoras aplicadas

Os espécimes ficaram armazenados individualmente em água destilada a $37^{\circ} \mathrm{C}$ por $24 \mathrm{~h}$ e receberam acabamento com discos de lixa SofLex Pop-On após este período. Cada espécime foi secionado duas vezes no sentido vestíbulo-lingual paralelamente ao longo eixo do dente originando 4 superfícies que foram mantidas em água destilada até o momento de medição de gaps (Fig.4.4). Nessa figura, as superfícies 1 e 2 são as superfícies externas e as superfícies 3 e 4 as internas. Esse procedimento 
geraria 120 observações $(=3 \times 2 \times 5 \times 4)$. Como 2 espécimes foram perdidos durante a condução do experimento, foram realizadas 118 observações.

A fim de remover resíduos que estivessem obstruindo os gaps na interface, foi realizado um novo condicionamento da superfície (ácido fosfórico a 37\%, na forma de gel, por 3s) e a seção a ser avaliada foi imersa numa solução de azul de metileno a $0,5 \%$ por 2 s, sendo em seguida lavada para remoção do excesso do corante que foi utilizado apenas com o intuito de evidenciar os gaps. A seção era então seca com papel absorvente e levada para observação.

Foi feita a medição dos gaps com aumento de 400x, utilizando o seguinte método: em cada campo observado dividia-se o gap em trechos de mesma largura (I) que era medida usando o sistema da indentação do microdurômetro (Shimadzu). O respectivo comprimento (c) era obtido medindo o deslocamento da platina do microscópio necessário para fazer avançar o gap no seu comprimento. (Fig. 4.5)

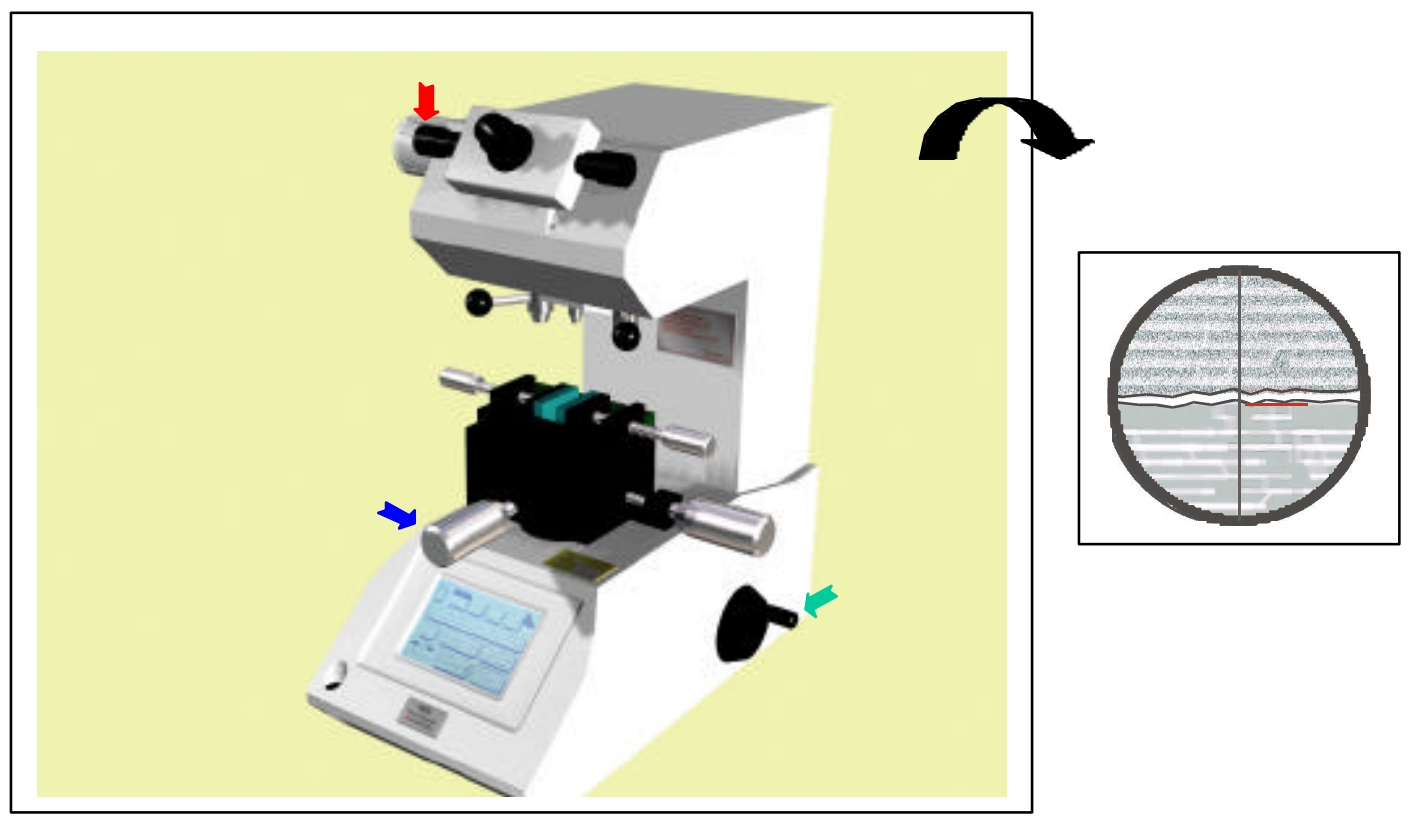

Figura 4.5 - Microdurômetro [O Barras paralelas $(1-\mu \mathrm{m})$ Cusos micrométricos (c-0,001mm); Foco; Esquema da interface observada ] 
O produto largura $\mathrm{x}$ comprimento de cada trecho do gap é uma medida da sua área. A largura média dos gaps em toda a interface (Im) foi calculada pelo somatório dessas áreas dividido pelo comprimento total, conforme expresso pela eq. 1.

$$
\operatorname{Lm}=\Sigma\left(c_{n} \cdot I_{n}\right) / \Sigma c_{n} \ldots \ldots .(1)
$$

Para determinar os comprimentos de trechos de larguras regulares do gap, foi necessário empregar uma estratégia. Já que nem sempre era possível deslocar o gap no sentido do comprimento, pelo avanço da platina apenas na direção do eixo $X$ ou apenas na direção do eixo $Y$, que era feito com auxílio da referência existente na ocular, anotavam-se os deslocamentos ocorridos nos eixos $\mathrm{X}$ e $\mathrm{Y}$, e calculava-se a hipotenusa do triângulo formado. O valor da hipotenusa era tido como o valor do comprimento correspondente àquele trecho.

Para analisar os efeitos das técnicas restauradoras na qualidade da interface, foi utilizada uma Análise de Variância para Medidas Repetidas ${ }^{56}$ com 3 fatores: Técnica para inserção com 3 níveis (incremental vertical, oblíqua e teste), Resina composta com 2 níveis (Z-250 e Durafill VS), e Superfície com 2 níveis (interna e externa). 


\section{RESULTADOS}

A estatística descritiva com as médias e desvios padrões da largura média dos gaps obtidos neste estudo estão apresentados na Tabela 5.1. Ela normalmente é o primeiro passo da análise estatística. Por meio das medidas-resumo pode-se depreender informações acerca do fenômeno em estudo e tirar as primeiras conclusões que serão confirmadas ou não pela inferência estatística. ${ }^{57}$

Tabela 5.1 - Estatísticas descritivas para largura média do gap

\begin{tabular}{cccccc}
\hline Técnica & Resina & Superfície & $\mathbf{n}$ & Média & Desvio-Padrão \\
\hline V & Durafill & externa & 10 & 4,77 & 0,96 \\
V & Durafill & interna & 10 & 5,34 & 0,94 \\
V & Z - 250 & externa & 10 & 5,52 & 1,35 \\
V & Z - 250 & interna & 10. & 5,77 & 1,46 \\
T & Durafill & externa & 10 & 7,26 & 2,05 \\
T & Durafill & interna & 10 & 8,08 & 2,15 \\
T & Z - 250 & externa & 10 & 6,16 & 1,24 \\
T & Z - 250 & interna & 8 & 6,68 & 2,68 \\
O & Durafill & externa & 10 & 6,34 & 0,75 \\
O & Durafill & interna & 10 & 6,35 & 0,95 \\
O & Z - 250 & externa & 10 & 5,58 & 1,50 \\
O & Z - 250 & interna & 10 & 7,18 & 3,34 \\
\hline
\end{tabular}


Os valores obtidos foram empregados na construção do gráfico de perfis apresentado na Fig. 5.1 .

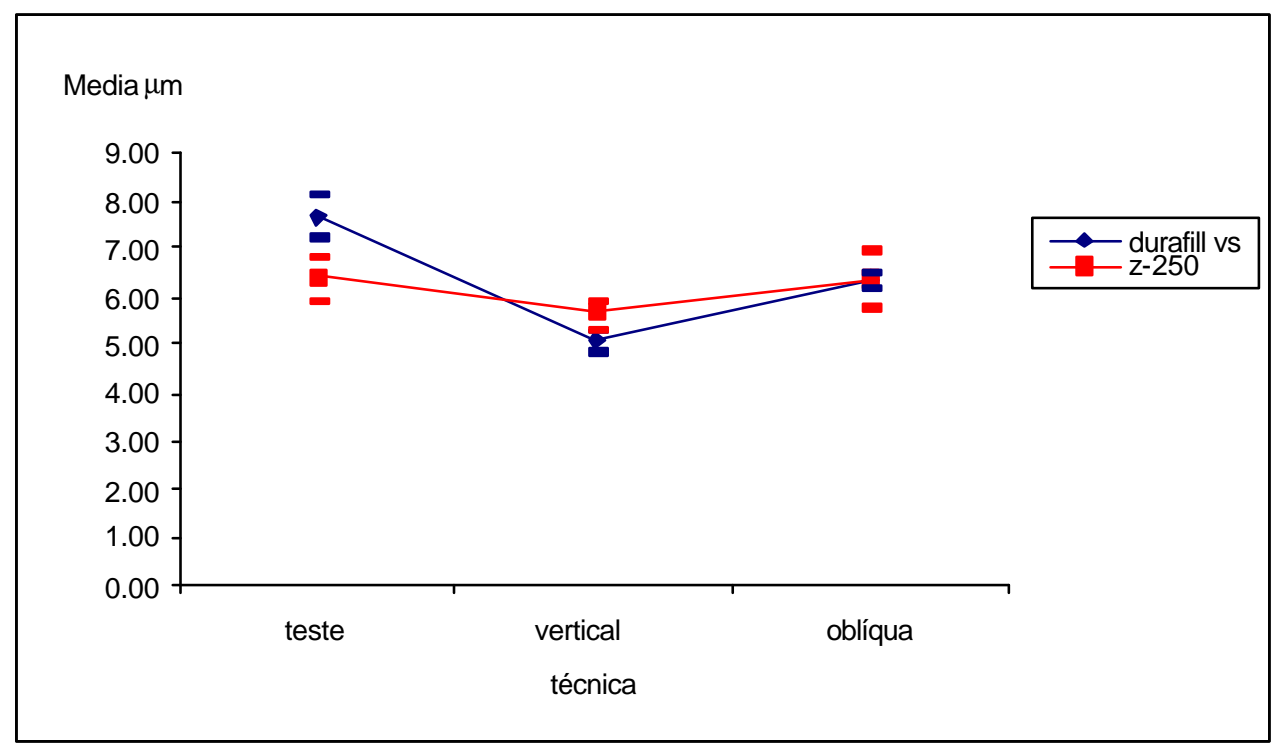

Figura 5.1 - Perfis médios da largura média de gaps

Os gráficos de perfis são muito comuns na literatura e auxiliam o entendimento das interações entre os fatores (ausência de interação corresponde a linhas paralelas). Diz-se que existe interação entre dois ou mais fatores, quando as médias de um ou mais fatores apresentam comportamento diferente dentro dos níveis de um outro fator.

A análise descritiva desse gráfico (Fig. 5.1) sugere que há interação entre os dois fatores considerados e, que a técnica teste mostrou pior desempenho com valores de largura média de gaps superiores aos das outras técnicas.

Com o objetivo de avaliar os efeitos dos fatores na largura média dos gaps foi realizada a Análise de Variância para Medidas Repetidas ${ }^{56}$ com 3 fatores fixos cruzados, a saber, Técnica, Resina e Superfície e um fator 
aleatório, Dente. O fator Superfície foi incluído como controle, pois faz parte das técnicas empregadas na obtenção dos dados.

Os resultados da análise de variância para a largura média dos gaps estão resumidos na tabela abaixo:

Tabela 5.2 - Análise de variância para a largura média de gaps

\begin{tabular}{rccrcc}
\hline & \multicolumn{2}{c}{ Graus de liberdade } & & \\
\cline { 2 - 4 } Fonte de Variação & Numerador & Denominador & F & p \\
\hline Técnica & 2 & 58 & 3,15 & 0,0503 \\
Resina & 1 & 58 & 0,06 & 0,8137 \\
Superfície & 1 & 48 & 6,02 & 0,0178 \\
Técnica *Resina & 2 & 58 & 0,66 & 0,5185 \\
Técnica *Superfície & 2 & 58 & 0,26 & 0,7726 \\
Resina*Superficie & 1 & 58 & 0,67 & 0,4171 \\
Técnica *Resina*Superficie & 2 & 58 & 1,05 & 0,3582 \\
\hline
\end{tabular}

Com relação à variável $(\mathrm{Im})$, os resultados indicam efeitos significativos de Técnica $(p=0,0503)$ e Superfície $(p=0,0178)$. Um modelo reduzido, que leva em conta apenas os fatores significativos foi ajustado aos dados, sugerindo que tratamentos baseados na técnica teste para inserção do material geram larguras médias dos gaps $1,51 \pm 0,56 \mu \mathrm{m}$ maiores que àqueles baseados na técnica para inserção vertical, que por sua vez são equivalentes àqueles baseados na técnica para inserção oblíqua para os quais a largura média dos gaps é de $5,52 \pm 0,43 \mu \mathrm{m}$.

Ainda segundo esse modelo, as larguras médias dos gaps nas superfícies internas são $0,69 \pm 0,27 \mu \mathrm{m}$ maiores do que aquelas correspondentes às superfícies externas cujo valor é 5,94 $\pm 0,23 \mu \mathrm{m}$ (Tabela 5.3.). 
Tabela 5.3 - Larguras médias dos gaps ajustados e intervalos de confiança $(95 \%)$

\begin{tabular}{cccccc}
\hline & & & Erro & \multicolumn{2}{c}{ Intervalo de Confiança de 95\% } \\
\cline { 5 - 6 } Técnica & Superfície & Média & Padrão & L. Inferior & L. Superior \\
\hline V & externa & 5,17 & 0,39 & 4,38 & 5,96 \\
V & interna & 5,86 & 0,50 & 4,87 & 6,87 \\
O & externa & 5,95 & 0,39 & 5,16 & 6,74 \\
O & interna & 6,64 & 0,50 & 5,64 & 7,63 \\
T & externa & 6,69 & 0,39 & 5,90 & 7,48 \\
T & interna & 7,38 & 0,50 & 6,38 & 8,37 \\
\hline
\end{tabular}




\section{DISCUSSÃo}

A combinação de resinas com diferentes ME nas técnicas restauradoras já foi bastante estudada com relação à do tipo flow. Os resultados positivos alcançados foram explicados pela transição gradual de rigidez da dentina para a resina de preenchimento da cavidade ${ }^{43}$ de modo que as deformações na resina flow ocorreriam preferencialmente às falhas na interface quando submetidas a tensões. ${ }^{52,45,46}$

No entanto, as resinas flow possuem maior CP do que aquelas para preenchimento, ${ }^{47}$ característica esta indesejável quanto ao desenvolvimento de tensões durante a polimerização. O desenvolvimento de tensões é tanto maior quanto maior for a CP e quanto maior for o ME da resina. ${ }^{48}$

A escolha das resinas utilizadas neste estudo obedeceu a dois critérios principais, distintos ME e mesma CP, visando observar o efeito da combinação de resinas com diferentes ME no desenvolvimento de tensões de CP por meio da análise da interface adesiva.

Segundo o estudo de Labella et al. (1999), ${ }^{47}$ a resina Durafill VS possui um ME de 6,5 GPa semelhante ao da sua versão tipo flowe a resina Z-100 um ME de 20,1 GPa. Esta diferença corresponde àutilizada em 1999 por Rees et al. ${ }^{49}$ (5 e $20 \mathrm{GPa}$ ) num estudo com elementos finitos. Os 
autores demonstraram diminuição importante de tensões com maiores espessuras da resina sem carga (20 a $80 \mu \mathrm{m})$. Portanto, as duas resinas mencionadas preencheriam o primeiro requisito desejado; contudo a contração volumétrica de ambas também foi significativamente distinta.

A utilização da resina Z-250 em substituição a resina Z-100 se baseou num teste preliminar realizado pelo método de Watts \& Cash (1991). ${ }^{55}$ Verificou-se que as resinas Z-250 e Durafill VS possuem a mesma CP $(p=0,999)$ e que a Z-100 apresenta CP significativamente maior que as outras duas $(p=0,001)$, resultados estes em conformidade com os achados de Labella et al., 1999. ${ }^{47}$ Vide Anexo.

Outro quesito considerado na escolha das resinas utilizadas neste estudo foi que o grau de atenuação das intensidades luminosas deveria ser semelhante para ambas, a fim de assegurar um mesmo alcance de irradiação em profundidade.

Esta consideração foi motivada pelos resultados contrastantes que o efeito da atenuação da intensidade de luz por cores mais escuras de RC apresentou em estudos anteriores, ${ }^{37,} 38$ possivelmente relacionados ঝ̀s espessuras do material empregado.

A fim de averiguar se as mesmas cores nominais $(A-3,0)$ das resinas escolhidas teriam o mesmo grau de atenuação foi realizado um teste preliminar em que se mediu, com o auxílio de um radiômetro, a intensidade de luz capaz de atravessar espécimes com espessura de aproximadamente $1 \mathrm{~mm}$ das resinas escolhidas. Observou-se que a mesma cor nominal (A3,0) possibilitava a passagem de uma intensidade de luz maior para a resina 
Durafill VS que para a resina Z-250 ( $p=0,03)$. Já as cores A-3,0 (Z-250) e A3,5 (Durafill VS) permitiram passagem de luz com intensidades semelhantes $(p=0,29)$, portanto, elas foram selecionadas para o estudo. Vide Anexo.

As técnicas para inserção vertical e oblíqua foram comparadas por vários autores à técnica de bloco único. Os resultados encontrados mostraram-se ora favoráveis à primeira ${ }^{11}$ ora favoráveis à segunda ${ }^{12}$ ou ainda não demonstraram diferenças entre elas. ${ }^{17}$ Mas, como são técnicas comumente utilizadas na prática clínica, foram adotadas neste estudo para fins comparativos.

Pensou-se que a técnica teste diminuiria a concentração de tensões na interface adesiva e favoreceria a integridade marginal, pelos seguintes mecanismos: 1) redução do fator cavitário efetivo, pois o forramento aumenta as superfícies livres; ${ }^{7}$ 2) em Z-t, o emprego da resina Durafill VS (menor ME) levaria à obtenção preferencial de deformação ao invés de um descolamento da interface adesiva protegida pela camada de Z-250 que seria suficientemente rígida para resistir às tensões de $\mathrm{CP}$ da resina de preenchimento e, 3) em D-t, a resina Durafill VS assumiria o papel de uma resina tipo flow ao absorver essas tensões, evitando que elas fossem transmitidas àinterface adesiva.

Embora as tensões geradas sejam o resultado clinicamente relevante da CP, sua mensuração é crítica. ${ }^{58,59}$ Por isso, na maioria das vezes seu estudo é feito de forma indireta através de seus efeitos, avaliados por testes de infiltração marginal, microtração e análise da interface. 
Diferentes técnicas para inserção foram comumente comparadas quanto àinfiltração marginal, 11, 12, 13, 15 numa diversidade de condições dos ensaios para simular "envelhecimento", o que dificulta sobremaneira a comparação efetiva dos resultados. Gale \& Darvell (1999) ${ }^{8}$ frisaram como aspecto negativo nesses estudos a ausência de um grupo imediato. Segundo eles permaneceria indefinido se as falhas na interface foram resultado da técnica e/ou material empregado ou do envelhecimento. Ressaltam ainda, que a presença de falhas num grupo imediato que permitisse diferenciar os tratamentos em estudo, dispensaria o uso de testes mais demorados, pois estes desempenhariam apenas o papel de uma agravante das falhas já existentes.

$\mathrm{Na}$ intenção de verificar a realidade de tal assertiva, optou-se neste estudo por realizar a leitura dos gaps em curto prazo. É importante considerar que, se por um lado o uso de ciclos térmicos poderia ampliar o gap, por outro lado a sorção de água poderia minimizá-lo. ${ }^{7,60}$ Como os resultados mostraram uma diferença significativamente marginal para o fator técnica (Tabela 5.1), também se poderia pensar que o emprego de técnicas para envelhecimento não permite uma diferença mais nítida.

A análise da interface adesiva por MEV foi utilizada também na avaliação de diferentes técnicas para inserção, ${ }^{17}$ contudo o preparo das amostras envolve a submissão das mesmas ao vácuo, que pode gerar artefatos técnicos mascarando os efeitos reais da CP. Assim, foi proposta neste estudo a mensuração da largura dos gaps ao longo de toda interface, 
microscopia óptica, incorporando àvariável resposta, por meio do cálculo da largura média de gaps da interface, a sua área.

No entanto, contrariamente æ̀s expectativas, a técnica teste apresentou maiores larguras médias de gaps ao longo da interface em comparação com a técnica vertical (Tabela 5.2). Como houve significância marginal para o fator Técnica $(p=0,050)$ não foi possível detectar diferenças entre a técnica teste e a oblíqua e entre a oblíqua e a vertical. Estes achados são semelhantes aos encontrados por Tjan et al. ${ }^{17}$

Uma primeira hipótese para explicar este achado seria a dificuldade técnica de se obter uma primeira camada de resina composta com espessura homogênea de aproximadamente $0,5 \mathrm{~mm}$. Segundo Opdam et al. (1996), ${ }^{61}$ tanto a consistência como a forma de aplicação da resina composta influi na presença de bolhas na interface. Assim, apesar dessa primeira camada ser obtida com o auxílio de uma ponta Centrix, conforme preconizado pelos autores, havia uma maior necessidade de manipulação com a espátula, a fim de afinar a camada de resina forrando as paredes cavitárias, que as demais técnicas, o que pode ter prejudicado a adaptação.

Outra possibilidade seria que a diferença de ME entre a resina Z-250 e a Durafill VS não teria sido suficiente para absorver as tensões de CP e preservar a interface adesiva.

Na literatura consultada, foi encontrado o valor de 14,1 GPa para o ME dinâmico da resina Z-250 e de 15,2 GPa para o da Z-100 que foram significativamente distintos, mas a resina Durafill VS não foi incluída no estudo. ${ }^{54}$ Estes valores são menores do que os encontrados por Labella et 
al. (1999) ${ }^{47}$ que obteve uma diferença acentuada entre os ME da Z-100 e da Durafill VS, contudo os métodos utilizados foram diferentes.

Esta segunda hipótese é apoiada também pelo fato de não se ter verificado influência das resinas nas larguras médias de gaps. Nas condições testadas, ambas as resinas geraram tensões que superaram a resistência de união. Se a diferença no $M E$ atendesse æ̀s expectativas iniciais, possivelmente haveria diferenças.

O fator cavitário utilizado, pode ser considerado bastante alto, reduzindo a possibilidade de alívio das tensões de CP pelo escoamento conforme demonstrado nos trabalhos de Feilzer et al. ${ }^{4,6}$

Contudo, a utilização da resina flow (Protect Liner) com fator-C semelhante apresentou menor infiltração marginal num estudo in vitro. ${ }^{51}$ Este resultado encontra-se de acordo com outro estudo com elementos finitos que observou redução das tensões de CP mesmo com fator cavitário de 3,7. ${ }^{49}$ Isto reforça a importância da viscosidade (handling features) abordada pelo estudo de Opdam et al. ${ }^{61}$ (1996) em que se verificou uma maior porcentagem de bolhas na interface quando foi utilizada uma resina de alta viscosidade (Herculite XRV), que foi atribuída a dificuldades de adaptação das mesmas æ̀s paredes da cavidade. ${ }^{61}$

Outra possibilidade para se explicar os resultados encontrados neste estudo é que talvez a magnitude da CP e a cinética da reação de polimerização tenham sido os fatores mais importantes na competição entre as tensões de CP e a resistência de união nas condições testadas. 
Como foi utilizada a fotoativação convencional neste estudo, provavelmente não houve tempo suficiente para que as tensões fossem aliviadas pelo escoamento, pois se sabe que a reação de polimerização nas resinas FA ocorre muito rapidamente. Num estudo já referenciado, ${ }^{47}$ foi mensurada a CP volumétricos ao longo do tempo para várias resinas e adesivos. Foi verificado que, embora cada material tenha apresentado uma curva de CP própria, para a maioria das resinas testadas $50 \%$ da CP total ocorria nos primeiros segundos de fotoativação. ${ }^{47}$

Neste estudo, a condição de análise superfície apresentou o nível descritivo mais significativo (Tabela 5.2). A largura geral média de gaps foi maior nas superfícies pertencentes àfatia central que a pertencente æ̀s fatias proximais, independentemente da técnica para inserção e da resina utilizada.

Pode-se explicar este achado pelo próprio desenvolvimento de tensões durante a polimerização da RC e seu alívio por meio do escoamento na superfície livre. Como nas paredes aderidas há restrição ao escoamento, a superfície livre tende a formar uma concavidade durante a polimerização cujo ponto mais profundo encontra-se no seu centro. ${ }^{62,27,23}$

Isto ocorre também no fundo da cavidade quando a resina não está aderida a ela. ${ }^{62}$ Como neste estudo a parede axial se encontra em dentina profunda e esta tende a apresentar menor resistência de união, ${ }^{63}$ muito provavelmente também houve tendência à formação desta concavidade resultando em maiores larguras médias de gaps quanto mais ao centro foi a superfície avaliada. 
Assim, como o desenvolvimento de tensões na restauração varia localmente, torna-se importante a utilização de mais de um corte nos estudos de avaliação de interface. Um único corte na região central da restauração, como é adotado em muitos estudos, ${ }^{50,15,18}$ poderia não ser representativo das falhas marginais daquela restauração por corresponder a uma região mais propensa a ocorrência das mesmas.

É muito importante considerar que embora o nível descritivo do fator Superfície tenha sido altamente significativo, a diferença calculada entre as superfícies internas e externas, cerca de 0,69um, poderia não ter relevância clínica, exceto pelo fato desta região ser, por si só uma das mais críticas nas restaurações de classe $\mathrm{V}$.

Por outro lado, as faces consideradas internas e externas na avaliação dos dados, estavam em contigüidade, separadas apenas pela espessura do disco de corte, de sorte que esta diferença poderia ser maior se fossem consideradas superfícies externas mais próximas às paredes cavitárias proximais.

Assim, a localização da superfície de leitura parece ser importante nos estudos de avaliação da interface adesiva, já que, nas condições experimentais adotadas neste estudo, esta foi a condição que mais afetou as larguras médias de gaps.

Algumas correlações importantes também necessitam investigação adicional, como a formação de gaps e infiltração de corante e a comparação entre a análise de interface por microscopia ótica usada neste estudo e pela MEV, por exemplo. Esclarecimentos mais detalhados destas questões 
contribuiriam para o aprimoramento das técnicas empregadas nos estudos e para a compreensão das limitações inerentes, aspectos estes fundamentais para entendimento do fenômeno da CP e de suas implicações clínicas. 


\section{Conclusões}

Os resultados deste estudo permitem concluir que:

1) O fator Técnica apresentou significância marginal, de sorte que se verificou diferença apenas para a técnica teste, com maior largura média de gaps, em relação àtécnica vertical.

2) Não houve influência da Resina na largura média de gaps.

3) O fator Superfície foi o mais significativo. As superfícies de leitura internas, pertencentes à seção central, apresentaram larguras médias de gaps maiores que as externas, pertencentes às seções proximais. 


\section{ANEXO}

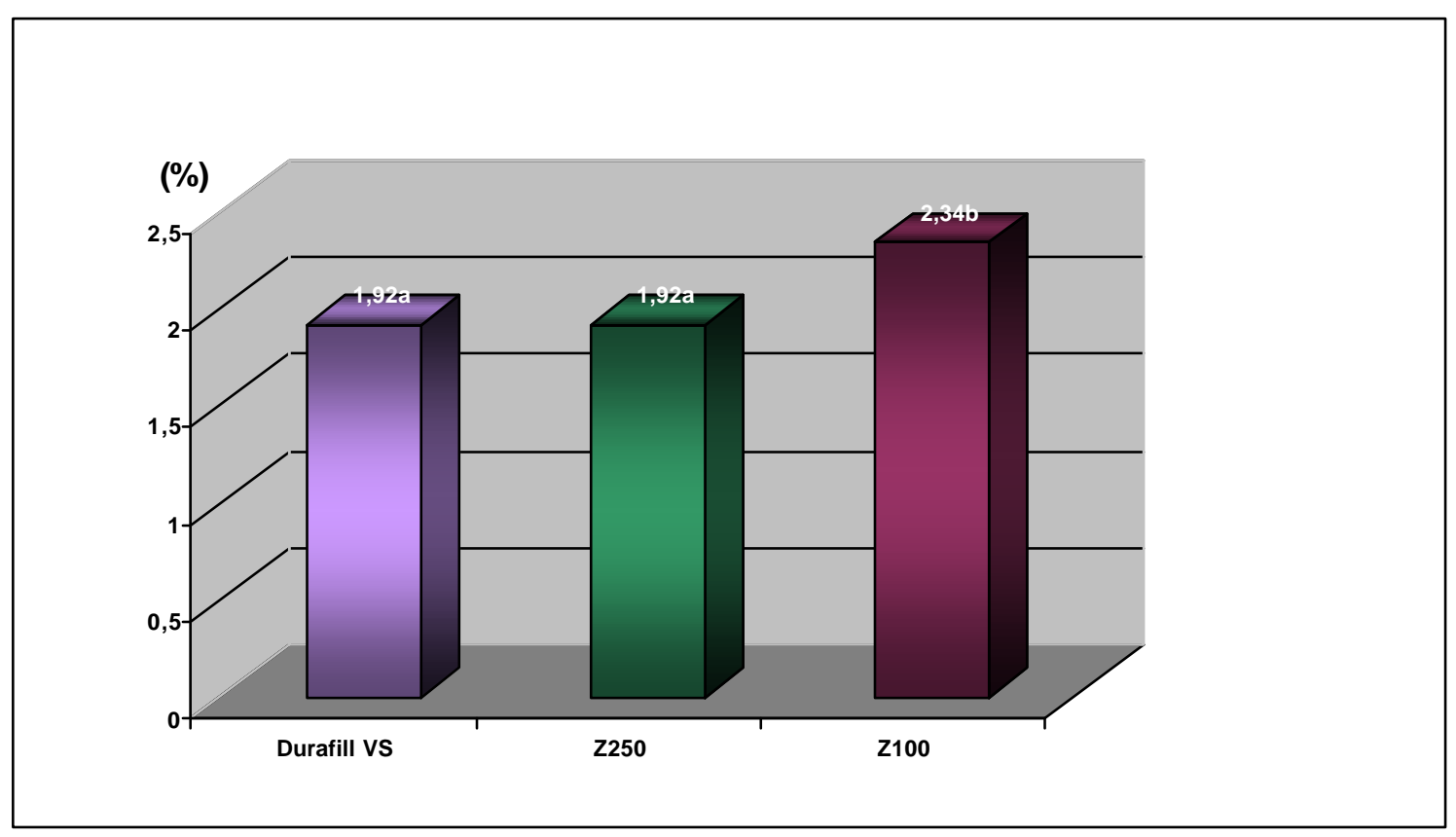

Figura An.1- Contração de polimerização (\%) conforme Watts \& Cash (1991)

Tabela An. 1 - Análise de variância da contração de polimerização

\begin{tabular}{cccccc}
\hline F.V. & G.L. & S.Q & Q.M & F & P \\
\hline Resina & 2 & 0,58804 & 0,29402 & 17,57 & $0,000^{*}$ \\
Erro & 12 & 0,20080 & 0,01673 & & \\
Total & 14 & 0,78884 & & & \\
\hline
\end{tabular}

Tabela An. 2 - Comparações múltiplas de Tukey

\begin{tabular}{ccc}
\hline & Durafill VS & Z-250 \\
\hline Z-100 & $0,0007^{*}$ & $0,0007^{*}$ \\
Durafill VS & - & $0,9987 n . s$. \\
\hline
\end{tabular}

*significante a $95 \%$

n.s. não significante 


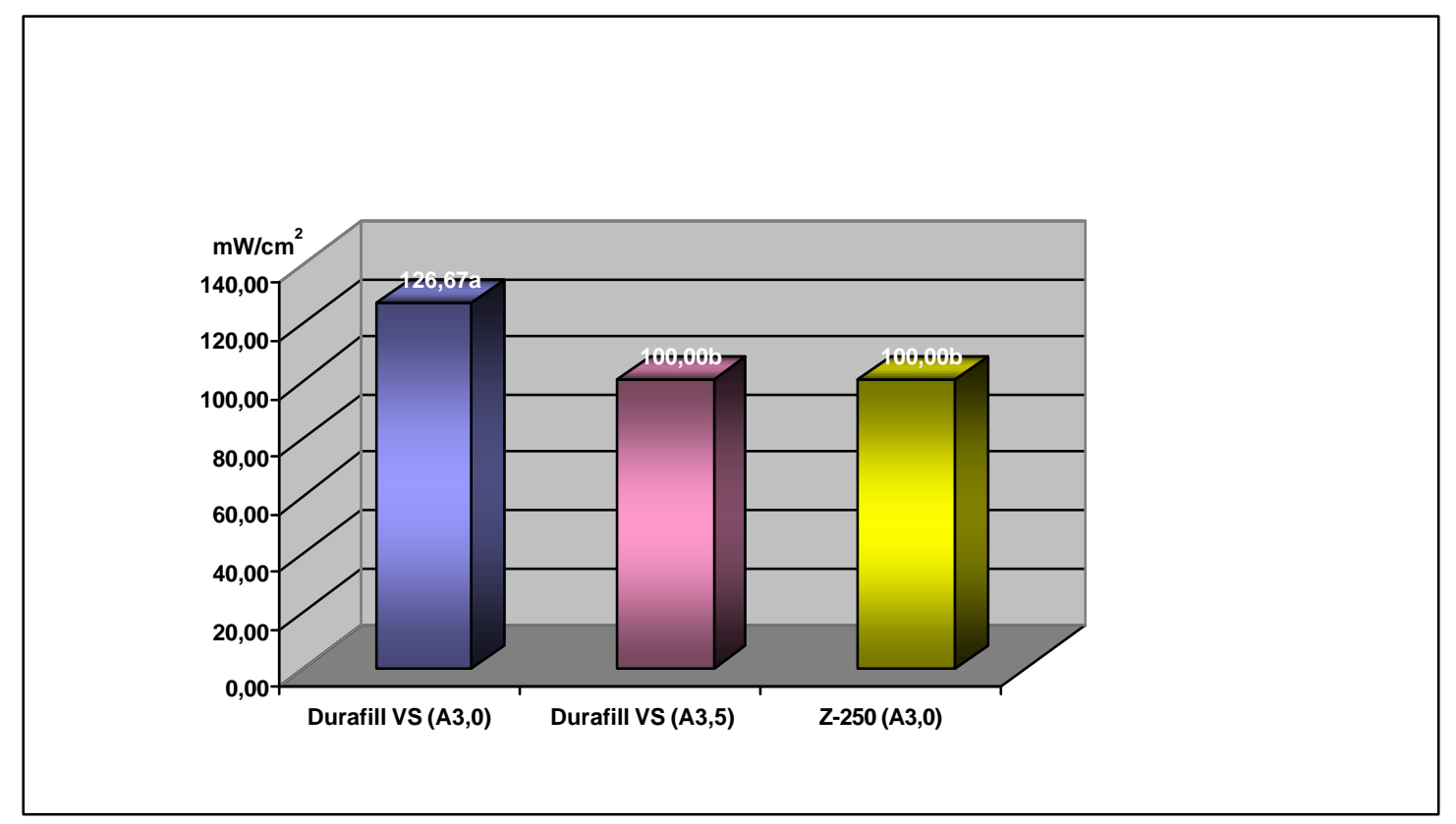

Figura An.2- Intensidade de luz capaz de atravessar $1 \mathrm{~mm}$ da resina $\left(\mathrm{mW} / \mathrm{cm}^{2}\right)$

Tabela An. 3 - Análise de variância da intensidade de luz

\begin{tabular}{cccccc}
\hline F.V. & G.L. & S.Q & Q.M & F & P \\
\hline Resina & 2 & 1422,22 & 711,11 & 9,14 & $0,015^{*}$ \\
Erro & 6 & 466,67 & 77,78 & & \\
Total & 8 & 1888,89 & & & \\
\hline
\end{tabular}

Tabela An. 4 -: Comparações múltiplas de Tukey

\begin{tabular}{lcc}
\hline & Durafill VS $(3,5)$ & Z-250 (A-3,0) \\
\hline Durafill VS $(3,0)$ & $0,0234^{*}$ & $0,0234^{*}$ \\
Durafill VS $(3,5)$ & - & 1,0000 n.s. \\
\hline
\end{tabular}

${ }^{*}$ significante a $95 \%$

n.s. não significante 


\section{REFERÊNCIAS *}

1. SUH, B. I.; FENG, L.; WANG, Y.; CRIPE, C.; CINCIONE, F.; RJIK, W. The effect of the pulse-delay cure technique on residual strain in composites. Compend Cont Educ Dent, Lawrenceville, v. 20, n. 2, p. 412, Feb. 1999.

2. DAVIDSON, C. L.; DE GEE, A. J. Relaxation of polymerization contraction stresses by flow in dental composites. J Dent Res, Chicago, v. 63, n. 2, p. 146-148, Feb. 1984.

3. DAVIDSON, C. L.; DE GEE, A. J.; FEILZER, A. The competition between the composite-dentin bond strength and the polymerization contraction stress. J Dent Res, Chicago, v. 63, n. 12, p. 1396-1399, Dec. 1984.

4. FEILZER, A. J.; DE GEE, A. J.; DAVIDSON, C. L. Setting stress in composite resin in relation to configuration of the restoration. J Dent Res, Chicago, v. 66, n. 11, p. 1636-1639, Nov. 1987.

5. FEILZER, A. J.; DE GEE, A. J. DAVIDSON, C. L. Quantitative determination of stress reduction by flow in composite restorations. J Dent Res, Chicago, v. 6, n. 3, p. 167-171, July 1990.

6. FEILZER, A. J.; DE GEE, A. J.; DAVIDSON, C. L. Setting stresses in composites for two different curing modes. Dent Mater, Copenhagen, v. 9, n. 1, p. 2-5, Jan. 1993.

7. CARVALHO, R. M.; PEREIRA, J. C.; YOSHIYAMA, M.; PASHLEY, D. H. A review of polymerization contraction: the influence of stress

* De acordo com ABNT NBR-6023: 2000. Abreviatura de periódicos segundo Bases de Dados MEDLINE. 
development versus stress relief. Oper Dent, Washington, v. 21, n. 1, p. 17-24, Jan./Feb. 1996.

8. GALE, M. S., DARVELL, B. W. Thermal cycling procedures for laboratory testing of dental restorations. J Dent, Bristol, v. 27, n. 2, p. 89-99, Feb. 1999.

9. LUTZ, F.; KREJCI, I.; LUESCHER, B.; OLDENBURG, T. R. Improved proximal margin adaptation of class II composite resin restorations by use of light-reflecting wedges. Quintessence Int, Carol Stream, v. 17, n. 10, p. 659-664, Oct. 1986.

10.LUTZ, F.; KREJCI, I.; OLDENBURG, T.R. Elimination of polymerization stresses at the margins of posterior composite resin restorations: a new restorative technique. Quintessence Int, Carol Stream, v. 17, n. 12, p. 777-784, Dec. 1986.

11. FISBEIN, S.; HOLAN, G.; GRAJOWER, R.; FUKS, A. The effect of VLC Scotchbond and an incremental filing technique on leakage around class II composite restorations. J Dent Child, Baltimore, v. 55, n. 1, p. 29-33, Jan./Feb. 1988.

12. LECLAIRE, C. C.; BLANK, L. W.; HARGRAVE, J. W.; PELLEU JR, G. B. Use of a two-stage composite resin fill to reduce microleakage below the cmentoenamel junction. Oper Dent, Washington, v. 13, n. 1, p. 20-23, Winter 1988.

13. KOENIGSBERG, S.; FUKS, A.; GRAJOWER, R. The effect of three filling techniques on marginal leakage around class II composite resin restorations in vitro. Quintessence Int, Carol Stream, v. 20, n. 2, p. 11721, Feb. 1989.

14.DONLY, K. J.; WILD, T. W.; JENSEN, M. E. Posterior composite class II restorations: in vitro comparison of preparation designs and restoration techniques. Dent Mater, Copenhagen, v. 6, n. 2, p. 88-93, Apr. 1990. 
15. EAKLE, W. S.; ITO, R. K. Effect of insertion technique on microleakage in mesio-occlusodistal composite resin restorations. Quintessence Int, Carol Stream, v. 21, n. 5, p. 369-374, May 1990.

16. CIUCCHI, B.; BOUILLAGUET, S.; DELALOYE, M.; HOLZ, J. Volume of the internal gap formed under composite restorations in vitro. J Dent, Bristol, v. 25, n. 3-4, p. 305-312, May/June 1997.

17.TJAN, A. H. L.; BERGH, B. H.; LIDNER, C. Effect of various incremental techniques on the marginal adaptation of class II composite resin restorations. J Prosthet Dent, St. Louis, v. 67, n. 1, p. 62-66, Jan. 1992.

18.WILSON, J. Effect of design features and restorative techniques on marginal leakage of $\mathrm{MO}$ composites: an in vitro study. Oper Dent, Washington, v. 18, n. 4, p. 155-159, July/Aug. 1993.

19.TERUYA, J. I. Influência de diferentes técnicas de inserção na infiltração marginal de restaurações de resina composta em cavidades classe II. 1994. 106 f. Dissertação (Mestrado em Materiais Dentários) - Faculdade de Odontologia, Universidade de São Paulo, São Paulo.

20.APPLEQUIST, E. A.; MEIERS, J. C. Effect of bulk insertion, prepolymerized resin composite balls, and beta-quartz inserts on microleakage of class V resin composite restorations. Quintessence Int, Carol Stream, v. 27, n. 4, p. 253-258, Apr. 1996.

21. MEIRA, J. B. C.; CARDOSO, P. E. C.; BALLESTER, R. Y. Microleakage of class II restorations using patterned porcelain inserts. J Dent Res, Chicago, v. 79, p. 190 Sp. Iss. 2000.

22. VERSLUIS, A.; DOUGLAS, W. H.; CROSS, M.; SAKAGUCHI, R. L. Does an incremental filling technique reduce polymerization shrinkage stresses? J Dent Res, Chicago, v. 75, n. 3, p. 871-878, Mar. 1996.

23.KATONA, T. R.; WINKLER, M. M. Stress analysis of bulk-filled class V light-cured composite restoration. J Dent Res, Chicago, v. 73, n. 8, p. 1470-1477, Aug. 1994. 
24.WINKLER, M.M., KATONA, T.R., PAYDAR, N.H. Finite element stress analysis of three filling techniques for class $\mathrm{V}$ light-cured composite restorations. J Dent Res, Chicago, v. 75, n. 7, p. 1477-1483, July 1996.

25.JEDRYCHOWSKI, J. R.; BLEIER, R. G.; CAPUTO, A. A. Shrinkage stresses associated with incremental composite filling techniques. J Dent Child, Baltimore, v. 65, n. 2, p. 111-115, Mar./Apr. 1998.

26. REES, J. S.; JACOBSEN, P. H. The effect of interfacial failure around a class $\mathrm{V}$ composite restoration analysed by the finite element method. $\mathbf{J}$ Oral Rehabil, Oxford, v. 27, n. 2, p. 111-16, Feb. 2000.

27.VERSLUIS, A.; TANTBIROJN, D.; DOUGLAS, W. H. Do dental composites always shrink toward the light? J Dent Res, Chicago, v. 77, n. 6, p. 1435-1445, June 1998.

28.KINOMOTO, Y.; TORII, M.; TAKESHIGE, F.; EBISU, S. Comparison of polymerization contraction stresses between self- and light-curing composites. J Dent, Bristol, v. 27, n. 5, p. 383-389, July 1999.

29.SEGURA, A.; DONLY, K. J.; CROLL, T. P. The effect of polymerization shrinkage during veneer placement. Quintessence Int, Carol Stream, v. 23, n. 9, p. 629-32, Sep. 1992.

30. FRANCO, E. B.; VIEIRA, S. R.; NAVARRO, M. F. L.; ISHIKIRIAMA, A. Avaliação da profundidade de polimerização e dureza de resinas compostas fotopolimerizáveis com e sem a interferência do esmalte dentário. Rev Bras Odontol, Rio de Janeiro, v. 48, n. 1, p. 24-27, Jan./Fev. 1991.

31.DE GOES, M. F.; RUBBI, E.; BAFFA, O.; PANZERI, H. Optical transmittance of reflecting wedges. Am J Dent, San Antonio, v. 5, n. 2, p. 78-80, Apr. 1992.

32. LÖSCHE, G. M. Marginal adaptation of class II composite fillings: guided polymerization vs reduced light intensity. J Adhes Dent, New Maldin, v. 1, n. 1, p. 31-39, 1999. 
33. UNTERBRINK, G. L.; MUESSNER, R. Influence of light intensity on two restorative systems. J Dent, Bristol, v. 23, n. 3, p. 183-189, June 1995.

34.FEILZER, A. J.; DOOREN, L. H.; DE GEE, A. J.; DAVIDSON, C. L. Influence of light intensity on polymerization shrinkage and integrity of restoration-cavity interface. Eur J Oral Sci, Copenhagen, v. 103, n. 5, p. 322-326, Oct. 1995.

35. ARAÚJO, R. M.; DE ARAÚJO, M. A. M.; MENDES, J. D. Influência da intensidade de luz de fotopolimerizadores na infiltração marginal. Rev Assoc Paul Cir Dent, São Paulo, v. 50, n. 5, p. 408-413, Set./Out. 1996.

36. GORACCI, G.; MORI, G.; DE MARTINIS, L. C. Curing light intensity and marginal leakage of resin composite restorations. Quintessence Int, Carol Stream, v. 27, n. 5, p. 355-362, May 1996.

37.DAVIDSON-KABAN, S.S.; DAVIDSON, C. L.; FEILZER, A. J.; DE GEE, A. J.; ERDILEK, N. The effect of curing light variations on bulk curing and wall-to-wall quality of two types and various shades of resin composites. Dent Mater, Copenhagen, v. 13, n. 6, p. 344-352, Nov. 1997.

38.TARLE, Z.; MENIGA, A; RISTIC, M.; SUTALO, J; PICHLER, G.; DAVIDSON, C. L. The effect of the photopolymerization method on the quality of composite resin samples. J Oral Rehabil, Oxford, v. 25, n. 6, p. 436-442, June 1998.

39.KORAN, P.; KÜRSCHNER, R. Effect of sequential versus continuous irradiation of a light-cured resin composite on shrinkage, viscosity, adhesion and degree of polymerization. Am J Dent, San Antonio, v. 11, n. 1, p. 17-22, Feb. 1998.

40. RUEGGEBERG, F. Contemporary issues in photocuring. Compend Cont Educ Dent, Lawrenceville, v. 20, n. 25, p. 4-15, Nov. 1999.

41. ChRistensen, R. P.; PAlMER, T. M.; PlOEGER, B. J.; YOST, M. P. Resin polymerization problems - are they caused by resin curing lights, resin formulations, or both? Compend Cont Educ Dent, Lawrenceville, v. 20, n. 25, p. 42- 54, Nov. 1999. 
42.WILlEMS, G.; LAMBRECHTS, P.; BRAEM, M.; CELIS, J. P. L.; VANHERLE, G. A classification of dental composites according to their morphological and mechanical characteristics. Dent Mater, Copenhagen, v. 8, n. 5, p. 310-319, Sep. 1992.

43. VAN MEERBEEK, B.; WILLEMS, G.; CELIS, J. P.; ROOS, J. R.; BRAEM, M.; LAMBRECHTS, P.; VANHERLE, G. Assessment by nano-indentation of the hardness and elasticity of the resin-dentin bonding area. $J$ Dent Res, Chicago, v. 72, n. 10, p. 1434-1442, Oct. 1993.

44.UNTERBRINK, G. L.; LIEBENBERG, W. H. Flowable resin composites as "filled adhesives": literature review and clinical recommendations. Quintessence Int, Carol Stream, v. 30, n. 4, p. 249-257, Apr. 1999.

45.KEMP-SCHOLTE, C.M.; DAVIDSON, C.L. Complete marginal seal of class $\mathrm{V}$ resin composite restorations effected by increased flexibility. $\mathbf{J}$ Dent Res, Chicago, v. 69, n. 6, p. 1240-1243, June 1990.

46.KEMP-SCHOLTE, C. M.; DAVIDSON, C. L. Marginal integrity related to bond strength and strain capacity of composite resin restorative systems. J Prosthet Dent, St. Louis, v. 64, n. 6, p. 658-664, Dec. 1990.

47.LABELLA, R.; LAMBRECHTS, P.; VAN MEERBEEK, B.; VANHERLE, G. Polymerization shrinkage and elasticity of flowable composites and filled adhesives. Dent Mater, Copenhagen, v. 15, n. 2, p. 128-137, Mar. 1999.

48.VERSLUIS, A.; TANTBIROJN, D. Theoretical considerations of contraction stress. Compend Cont Educ Dent, Lawrenceville, v. 20, n. 25, p. 24-32, Nov. 1999.

49.REES, J. S.; O'DOUGHERTY, D.; PULLIN, R. The stress reducing capacity of unfilled resin in a class V cavity. J Oral Rehabil, Oxford, v. 26, n. 5, p. 422-427, May 1999.

50. CHOI, K. K.; CONDON, J. R.; FERRACANE, J. L. The effects of adhesive thickness on polymerization contraction stress of composite. J Dent Res, Chicago, v. 79, n. 3, p. 812-817, Mar. 2000. 
51.BELLI, S.; INOKOSHI, S.; ÖZER, F.; PEREIRA, P. N. R.; OGATA, M.; TAGAMI, J. The effect of additional enamel etching and a flowable composite to the interfacial integrity of class II adhesive composite restorations. Oper Dent, Washington, v. 26, n. 1, p. 70-75, Jan./Feb. 2001.

52. MONTES, M. A. J. R.; de GOES, M. F.; da CUNHA, M. R. B.; SOARES, A. B. A morphological and tensile bond strength evaluation of an unfilled adhesive with low-viscosity composites and a filled adhesive in one and two coats. J Dent, Bristol, v. 29, n. 6, p. 435-441, Aug. 2001.

53.WATTS, D.C. Elastic moduli and visco-elastic relaxation. J Dent, Bristol, v. 22, n. 3, p.154-158, June 1994.

54.POSKUS, L. T.; CARDOSO, P. E. C.; MALlMANN, A.; LiMA, L. F. C. Módulo elástico dinâmico de compostos em função do tratamento térmico pós-polimerização. Pesqui Odontol Bras, São Paulo, v. 14, p. 71, supl. 2000.

55.WATTS, D. C.; CASH, A. J. Determination of polymerization shrinkage kinetics in visible-light-cured materials: methods development. Dent Mater, Copenhagen, v. 7, n. 4, p. 281-287, Oct. 1991.

56.DIGGLE, J. P.; LIANG, K. Y.; ZEGER, S. L. Analysis of longitudinal data. Oxford: Clarendon Press, 1994. 253 p.

57. MAGALHÃES, M. N.; LIMA, A. C. P. Noções de Probabilidade e Estatística. São Paulo: IME-USP, 2000. 375 p.

58.DAVIDSON, C. L.; FEILZER, A. J. Polymerization shrinkage and polymerization shrinkage stress in polymer-based restoratives. J Dent, Bristol, v. 25, n. 6, p. 435-440, Nov. 1997.

59.SAKAGUCHI, R. L. A review of the curing mechanics of composites and their significance in dental applications. Compend Cont Educ Dent, Lawrenceville, v. 20, n. 25, p.16-23, Nov. 1999. 
60.TORSTENSON, B.; BRÄNNSTRÖM, M. Contraction gap under composite resin restorations: effect of hygroscopic expansion and thermal stress. Oper Dent, Washington, v. 13, n.1, p. 24-31, Winter 1988.

61. OPdAM, N. J.; ROETERS, J. J.; PETERS, T. C,; BURGERDIJK, R. C. W.; TEUNIS, M. Cavity wall adaptation and voids in adhesive Class I resin composite restorations. Dent Mater, Copenhagen, v. 12, n. 4, p. 230-235, July 1996.

62.SUH, B. I.; WANG, Y. Determining the direction of shrinkage in dental composites by changes in surface contour for different bonding configurations. Am J Dent, San Antonio, v. 14, n. 2, p. 109-113, Apr. 2001.

63. YOSHIKAWA, T.; SANO, H.; BURROW, M. F.; TAGAMI, J.; PASHLEY, D. H. Effects of dentin depth and cavity configuration on bond strength. $\mathbf{J}$ Dent Res, Chicago, v. 78, n. 4, p. 898-905, Apr. 1999. 


\section{APÊNDICE}

Tabela Ap. 1 : Análise de variância para a largura média do gap (matriz de covariância não estruturada)

\begin{tabular}{|c|c|c|c|c|}
\hline \multirow[b]{2}{*}{ Fonte de Variação } & \multicolumn{2}{|c|}{ Graus de liberdade } & \multirow[b]{2}{*}{$\mathbf{F}$} & \multirow[b]{2}{*}{$\mathbf{p}$} \\
\hline & Numerador & Denominador & & \\
\hline Técnica & 2 & 24 & 2,08 & 0,1464 \\
\hline Resina & 1 & 24 & 0,28 & 0,5999 \\
\hline Superfície & 1 & 24 & 1,43 & 0,2432 \\
\hline Técnica *Resina & 2 & 24 & 0,28 & 0,7594 \\
\hline Técnica *Superfície & 2 & 24 & 0,01 & 0,9881 \\
\hline Resina*Superficie & 1 & 24 & 0,53 & 0,4727 \\
\hline Técnica *Resina*Superficie & 2 & 24 & 1,42 & 0,2618 \\
\hline
\end{tabular}

Uma análise de resíduos, para a largura média de toda interface, indicou dois possíveis pontos discrepantes (outliers) correspondentes aos tratamentos (técnica para inserção vertical, resina composta Z - 250 e superfície externa) e (técnica teste para inserção, resina composta Z - 250 e superfície externa) com valores de 14,48 e 13,02, respectivamente.

Foi também considerada uma matriz de covariância intra-unidades experimentais não estruturada e, as análises com propósito de avaliação da sensibilidade do modelo foram refeitas. Os resultados inerentes à ANOVA não mudam consideravelmente, confirmando as conclusões apresentadas no capítulo de resultados. 
Tabela Ap. 2 - Covariâncias e correlações amostrais com os dados completos

\begin{tabular}{cccc}
\hline Superfície 1 & Superfície 2 & Superfície 3 & Superfície 4 \\
\hline 1,92 & 0,98 & 2,34 & 1,07 \\
0,38 & 2,24 & 2,26 & 1,74 \\
0,79 & 0,55 & 6,33 & 3,17 \\
0,57 & 0,38 & 0,76 & 2,71 \\
\hline
\end{tabular}

Tabela Ap. 3 - Covariâncias e correlações amostrais ajustadas pelo modelo inicial

\begin{tabular}{cccc}
\hline Superfície 1 & Superfície 2 & Superfície 3 & Superfície 4 \\
\hline 1,96 & 1,10 & 1,98 & 1,98 \\
0,56 & 1,96 & 1,98 & 1,98 \\
0,62 & 0,62 & 5,22 & 4,37 \\
0,62 & 0,62 & 0,84 & 5,22 \\
\hline
\end{tabular}

Nas Tabelas Ap. 2 e 3, as variâncias se encontram na diagonal principal, as covariâncias acima e as correlações abaixo. 


\section{SUMMARY}

\section{EVALUATION OF THE ADHESIVE INTERFACE OF RESTORATIONS COMBINING COMPOSITE RESINS WITH DIFFERENT ELASTIC MODULUS}

The objective of this study was to evaluate the quality of the adhesive interface of an experimental placement technique, which combines different composite resins, and two conventional techniques used in class $\mathrm{V}$ restorations in bovine teeth. Two composite resins were applied in this study (Z-250 and Durafill VS) with the adhesive system (Single Bond) in 30 cavity preparations made on the labial surface of the teeth $(\mathrm{C}$-factor $=3)$. So, six restorative techniques were applied with 5 samples each: incremental vertical (Z-v e D-v), incremental oblique (Z-o e D-o), and experimental [Z-e and D-e (lining the cavity walls with one of the resins and bulk filling with the other)]. After 24-hour-storage in water $\left(37^{\circ} \mathrm{C}\right)$, each specimen was sectioned (LB) generating 4 surfaces for gap assessment that were previously acid etched (phosphoric acid $37 \%$ for $3 \mathrm{~s}$ ) and stained (metilene blue $0.5 \%$ for $2 \mathrm{~s}$ ). The adhesive interface was examined by optic microscopy at $400 \mathrm{x}$ and both length (I) and width (w) of gaps were measured $(\mu \mathrm{m})$. The mean gap widths 
were calculated by the equation $w=\Sigma\left(c_{n} \times I_{n}\right) / \Sigma c_{n}$. The results obtained from the data's statistical analysis (ANOVA for Repeated Measurements) showed that only Technique and Surface were significant $(p<0,05)$. Based in this results it was concluded that the experimental technique showed the worst interface quality, which means that gap widths were larger and that the gap width means of the central section were higher than the measured external ones. 


\section{AUTORIZAÇÃO}

Autorizo a reprodução e/ou divulgação total ou parcial da presente obra, por qualquer meio convencional ou eletrônico, desde que citada a fonte e comunicada, ao autor, a referência em que consta a citação.

Silvia Kenshima

Assinatura

FOUSP / Departamento de Materiais Dentários

São Paulo, 12 de Novembro de 2001.

E-mail: Silvia.k@uol.com.br 